\title{
Avaliação e caracterização de reservatórios laminados: comparação entre as ferramentas convencionais e o perfil de indução multicomponente
}

\author{
Margareth da Silva Brasil Guimarães ${ }^{1}$, Paulo Sergio Denicol ${ }^{I}$ \&icardo Manhães Ribeiro Gomes ${ }^{1}$
}

\begin{abstract}
Resumo Algumas das reservas de hidrocarbonetos no Brasil estão contidas em formações interlaminadas presentes nos turbiditos da bacia de Campos. Comumente, nessas sequências, as camadas laminadas são tão delgadas que as ferramentas de indução convencionais não têm resolução vertical suficiente para resolvê-las individualmente. Normalmente, essas sequências exibem anisotropia de resistividade, ou seja, a resistividade horizontal, paralela ao acamamento, é usualmente menor do que a resistividade vertical, perpendicular ao acamamento. Em particular, isto é verdade quando a areia é portadora de hidrocarbonetos, uma vez que a resistividade é substancialmente afetada pela presença de folhelhos condutores. Ou seja, não considerar a anisotropia pode levar a uma subestimação dos volumes de óleo presentes no reservatório. A ferramenta de indução multicomponente foi desenvolvida para detectar a anisotropia de resistividade em uma formação interlaminada. Ela consiste em três conjuntos de transmissores/receptores mutuamente ortogonais cuja configuração permite a aquisição das resistividades horizontal e vertical da sequência. A partir destas, é possível determinar a resistividade real da lâmina de areia e consequentemente quantificar a saturação de hidrocarbonetos de maneira mais realista nestes reservatórios. Os resultados mostram que a saturação de hidrocarbonetos baseada nos dados da ferramenta de indução multicomponente são significativamente maiores do que aquelas baseadas nos dados de indução convencional. Portanto, uma avaliação petrofísica baseada somente na resistividade horizontal pode subestimar consideravelmente as reservas de hidrocarbonetos em reservatórios deste tipo.
\end{abstract}

Palavras-chave: reservatórios interlaminados, anisotropia de resistividade, indução multi-componente.

\begin{abstract}
Avaliation and characterization of laminated reservoirs: comparison between conventional and multi-component induction tools. In Campos Basin hydrocarbon reserves can occur in interlaminated formations associated to turbidity sequences. Usually the layer thickness within these laminated sand-shale sequences are below the vertical resolution of the standard induction tools. In addition, these sequences show electrical anisotropy, with the horizontal resistivity, parallel to bedding planes, less than the vertical resistivity, perpendicular to bedding planes. This is particularly true when the sand is hydrocarbonbearing, since the horizontal resistivity is substantially affected by the presence of conducting shales. So, if the anisotropy is not considered the volume of oil in the reservoir can be substantially underestimated. The multi-component induction tool has been developed to detect the resistivity anisotropy in a sand-shale sequence. It consists of three mutually orthogonal transmitter-receivers configuration that allows the acquisition of horizontal and vertical resistivity of the formation. Based on the horizontal and vertical resistivities, it is possible to determine the true sand resistivity and consequently quantify the hydrocarbon saturation in a more realistic approach for these reservoirs. Results have shown that the hydrocarbon saturation based on the multicomponent induction tool is significantly higher than that based on the conventional induction measurements. Therefore, a petrophysical evaluation using only the horizontal resistivity can considerably underestimate the hydrocarbon reserves in these kinds of reservoirs.
\end{abstract}

Keywords: laminated reservoirs, resistivity anisotropy, multi-component induction tool

INTRODUÇÃO Os reservatórios de águas profundas da Bacia de Campos, constituídos de turbiditos e fácies de águas profundas associadas, compreendem as mais importantes acumulações de petróleo do Brasil, alcançando aproximadamente $80 \%$ das reservas de óleo (Bruhn 1998).

A explotação eficiente desses hidrocarbonetos depende, dentre vários fatores, do conhecimento das heterogeneidades faciológicas dos reservatórios. Turbiditos depositados em sistemas de águas profundas podem ser muito complexos, tendo sua faciologia variando desde arenitos maciços até grandes seqüências interlaminadas de arenitos e folhelhos (Gomes et al. 2002, Ferraris et al. 2007).

A identificação de zonas portadoras de hidrocarbonetos é dificultada em casos de intercalações delgadas de arenitos e folhelhos, o que pode mascarar a presença de potenciais reservatórios.

As ferramentas de indução convencionais não são capazes, na maioria das vezes, de resolver as ca- 
madas de arenitos em função de sua pequena resolução vertical (Klein 1996, Gomes et al. 2002, Ferraris et al. 2007). Além disso, estas ferramentas medem a resistividade das camadas através de um processo de indução em circuito paralelo de corrente, que prioriza a presença dos folhelhos condutores e, segundo Yu et al. (2001) é quase insensível à resistividade dos arenitos com óleo.

Portanto, estas seqüências interlaminadas exibem forte anisotropia elétrica quando a areia está saturada por hidrocarboneto, porque a resistividade paralela ao acamamento tende a ser menor do que a resistividade perpendicular ao acamamento. Uma vez que as ferramentas de indução convencionais medem somente a resistividade horizontal, a determinação da saturação de água e conseqüentemente a determinação do "net pay" tendem a ser erroneamente quantificados, levando a uma interpretação subestimada do potencial petrolífero do reservatório (Gomes et al. 2002). Segundo Mollison \& Mezzatesta (2000), em muitos casos, as reservas de hidrocarbonetos podem ser subestimadas em até $40 \%$ neste tipo de reservatório.

Este trabalho consiste em caracterizar os reservatórios turbidíticos, em especial as porções interlaminadas observadas em um poço localizado no campo Gabriel, Bacia de Campos, através de uma análise quantitativa de perfis convencionais e, em seguida, verificar se ocorre um incremento de "net pay" quando as ferramentas convencionais são analisadas de maneira integrada com perfis especiais, tais como ressonância magnética, indução multicomponente e perfis de imagem. Adicionalmente, informações de testemunhos e de registros de pressão são utilizadas para corroborar a presença das possíveis zonas de interesse reconhecidas através dos perfis.

BACIA DE CAMPOS-EVOLUÇÃO TECTONOSEDIMENTAR A Bacia de Campos, localizada ao longo da plataforma continental do Rio de Janeiro, sudeste do Brasil, está limitada, ao norte, pelo Alto de Vitória, que a separa da bacia do Espírito Santo, e ao sul, pelo Alto de Cabo Frio, separando-a da bacia de Santos (Rangel et al. 1994). A bacia cobre uma área de aproximadamente $100.000 \mathrm{~km}^{2}$, dos quais $500 \mathrm{~km}^{2}$ são em área emersa (Milani et al. 2000) e corresponde à principal província petrolífera do Brasil, compreendendo aproximadamente $80 \%$ das reservas de óleo do país (Bruhn 1998).

A origem e evolução da bacia de Campos está associada a ruptura do Gondwana, com a separação das placas sul americana e africana, e a subsequente abertura do Atlântico Sul. Este processo teve início no fim do Jurássico e envolveu um intenso vulcanismo com o derrame de lavas basálticas da Formação Cabiúnas, que constitui o embasamento da bacia. A fase rifte engloba a Formação Lagoa Feia e abarca o intervalo Neocominiano Superior-Barremiano. A porção inferior da Formação Lagoa Feia é representada por uma espessa sequência de terrígenos (arenitos e folhelhos ricos em matéria orgânica) e carbonatos (coquinas), depositados em um ambiente de sedimentação lacustre (Membro Coqueiros). Já a porção superior está representada por uma sequência de conglomerados e folhelhos avermelhados, de idade Aptiana, recobertos por uma seção de evaporitos, provenientes das primeiras incursões marinhas devido ao início do espalhamento do assoalho oceânico (Membro Retiro). Durante o Albiano, as condições marinhas prevaleceram na bacia dando origem a plataforma carbonática da fase marinha restrita, originando a Formação Macaé. Esta formação compreende os carbonatos clásticos e oolíticos do Membro Quissamã, que localmente aparecem dolomitizados, e sobrejacentemente a este, encontra-se uma sucessão de calcilutitos, margas e folhelhos do Membro Outeiro e arenitos turbidíticos do Membro Namorado. Nas porções mais proximais, é constituída por conglomerados e arenitos do Membro Goitacás. A partir do Cretáceo Superior até o Recente prevaleceu uma sedimentação marinha aberta com a deposição de siliciclásticos (Grupo Campos) que recobre discordantemente a Formação Macaé. É representado por sedimentos areno-conglomerático-carbonáticos da Formação Emborê gradando para folhelhos e margas nas porções mais distais (Formação Ubatuba) e intercalados com arenitos turbidíticos do Membro Carapebus (Souza Cruz 1995, Milani et al. 2000). Na figura 1 podem-se observar as unidades litoestratigráficas utilizadas atualmente na Bacia de Campos.

CAMPO GABRIEL O campo Gabriel (nome fictício) está situado na área norte da bacia de Campos (Fig. 2), a cerca de $120 \mathrm{~km}$ do cabo de São Tomé, litoral norte do Estado do Rio de Janeiro e ocupa uma área de 215 $\mathrm{km}^{2}$.

Segundo Arienti (comunicação pessoal, 2007) as seqüências deposicionais de alta resolução do Oligoceno e Mioceno da Bacia de Campos englobam importantes campos de petróleo em "sistemas deposicionais turbidíticos" de águas profundas. A estruturação e o estilo deposicional foram, principalmente, controlados por tectônica de sal. No Oligo-Mioceno/Mioceno da Bacia de Campos observa-se uma correlação entre o arcabouço estrutural da fase rifte com a fase pós-rifte, onde as falhas do Oligo-Mioceno parecem ter se desenvolvido não só pela movimentação do sal, mas também por reativações do embasamento ao longo da história da bacia, criando depocentros e originando caminhos preferenciais das fontes de sedimentos para a bacia. A partir daí, foram criadas condições para o estaqueamento de espessuras consideráveis de arenitos turbidíticos.

Os reservatórios produtores do Campo Gabriel são arenitos miocênicos pertencentes à Formação Carapebus, constituídos por arenitos dominantemente finos, depositados por correntes de turbidez e correntes de fundo (Arienti 2007, comunicação pessoal). Diferentes fácies de arenitos são observadas variando de espessas camadas maciças de areia até sequências interlaminadas de areias e folhelhos (Gomes et al. 2002, Ferraris et al. 2007).

A sequência deposicional desses corpos areno- 


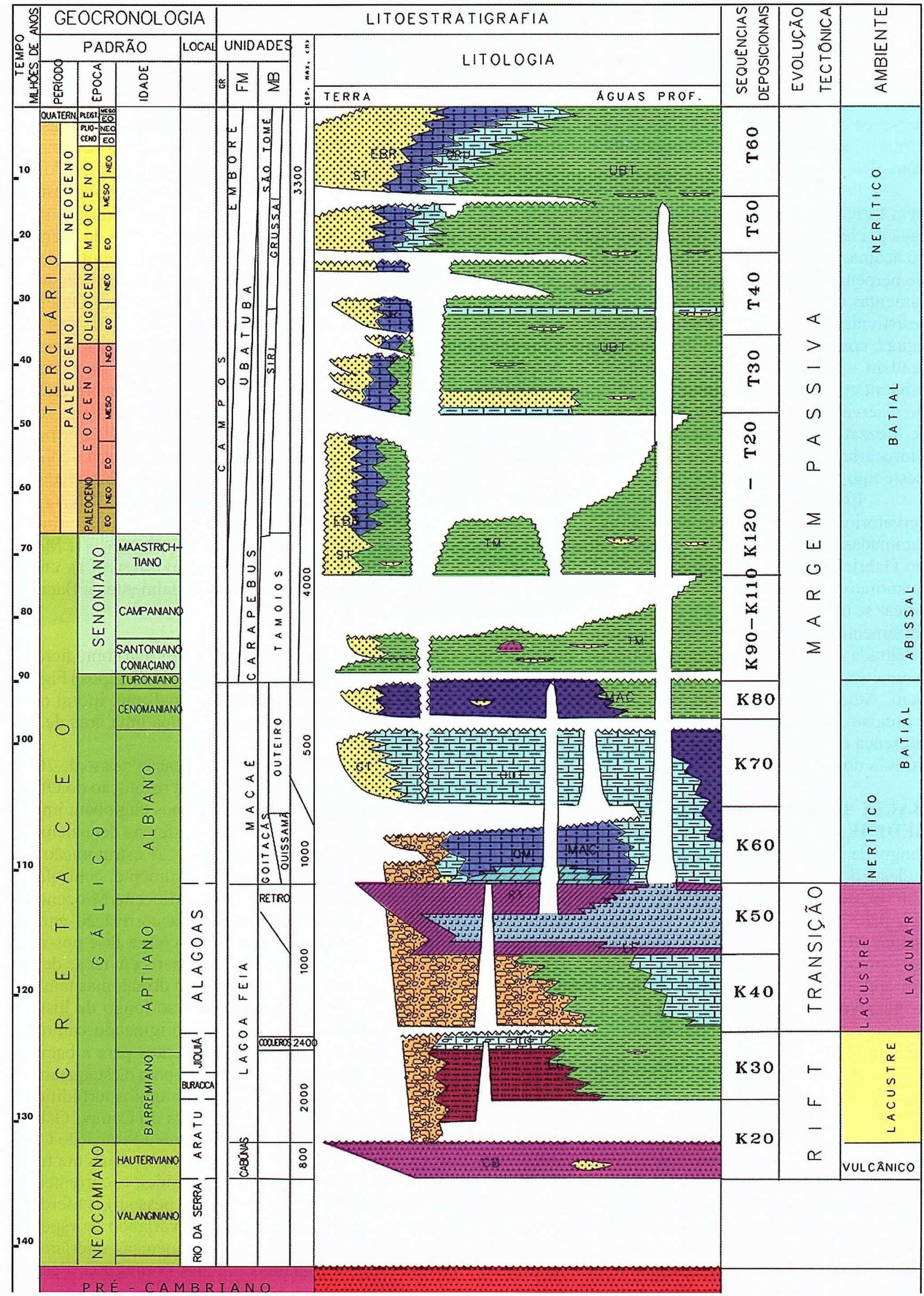

Figura 1 - Carta estratigráfica da bacia de Campos (Rangel et al., 1994 modificado). 


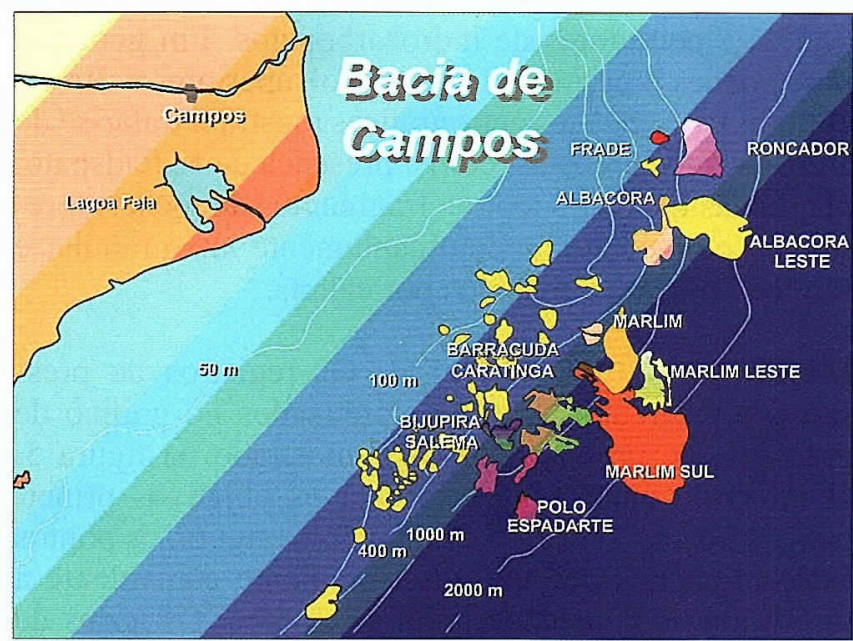

Figura 2 - Localização de diversas áreas exploratórios da Bacia de Campos (cedida por Souza Cruz).

sos inicia-se com o preenchimento de áreas rasas geradas pela tectônica de sal, seguido pelos depósitos de canais ricos em areia, que constituem o principal estágio da deposição dos reservatórios. Os arenitos são inconsolidados e apresentam espessuras menores que 20 metros, frequentemente limitadas por pinch-outs ou por processos erosivos. O último estágio é caracterizado pelo decréscimo no suprimento de areia e pela deposição de areias interlaminadas com siltitos e folhelhos, associados a depósitos de overbank. Esses depósitos caracterizam uma zona de baixa resistividade, difícil de avaliar utilizando apenas as ferramentas de indução convencionais e podem ser erroneamente interpretados como "non pay zones" devido aos altos volumes de argila e saturação de água calculados. Também, estes intervalos mostram uma diferença significativa entre as permeabilidades vertical e horizontal (Ferraris et al. 2007).

CONCEITO DE ANISOTROPIA A anisotropia é definida como uma variação das propriedades petrofísicas das rochas com a direção da medida. Em particular, a anisotropia elétrica ocorre quando a resistividade vertical, medida perpendicularmente ao acamamento da formação, é maior que a resistividade horizontal, medida paralelamente ao acamamento da formação (Klein 1996), conforme equação 1 :

$$
\text { anisotropia }=\frac{R v}{R h}
$$

em que as resistividades vertical (Rv) e horizontal (Rh) são dadas pela equações 2 e 3 :

$$
\begin{aligned}
& \mathrm{e}^{R v}=V s h \times R s h+(1-V s h) \times R s d \\
& \frac{1}{R h}=\frac{V s h}{R s h}+\frac{1-V s h}{R s d},
\end{aligned}
$$

onde Rsh e Rsd correspondem a resistividade do folhelho e das lâminas de arenito, respectivamente e Vsh corresponde a fração volumétrica do folhelho laminar (Hagiwara 1994 apud Yu et al. 2001, Mollison \& Mezzatesta 2000).

Sequências de arenitos e folhelhos interlaminados exibem anisotropia elétrica quando as camadas de arenito são saturadas com hidrocarbonetos. As baixas resistividades dos folhelhos dominam a resistividade horizontal enquanto as camadas de areia portadoras de hidrocarbonetos dominam a resistividade vertical ( $\mathrm{Yu}$ et al. 2001).

Em poços perfurados perpendicularmente ao acamamento, as ferramentas de indução convencionais medem apenas a resistividade horizontal, tornando-se um desafio quanto a determinação da saturação de água e de "net pay" nos reservatórios finamente laminados, levando a uma avaliação incorreta das reservas de hidrocarbonetos.

\section{FERRAMENTA DE INDUÇÃO MULTICOMPO-}

NENTE A ferramenta de indução multicomponente da Baker-Atlas (3DEX) consiste em três conjuntos de transmissores/receptores mutuamente ortogonais (Kriegshäuser et al. 2000) que permitem a aquisição de cinco componentes do campo magnético, a saber: Hxx, Hyy, Hzz, Hxy, e Hxz (Fig. 3). O primeiro índice indica a direção do transmissor e o segundo, a direção do receptor e a direção z é paralela ao eixo da ferramenta (Gomes et al. 2002).

A componente de resistividade paralela ao eixo do poço (Hzz) é responsável pela indução das correntes que fluem paralelamente ao acamamento e as componentes de resistividade perpendiculares ao eixo do poço (Hxx e Hyy), pelas correntes que fluirão paralela e perpendicularmente ao acamamento (Fig. 4). Geralmente, os dados provenientes da componente Hzz são similares aos dados da ferramenta de indução convencional sendo, portanto, sensíveis somente a Rh. Por outro

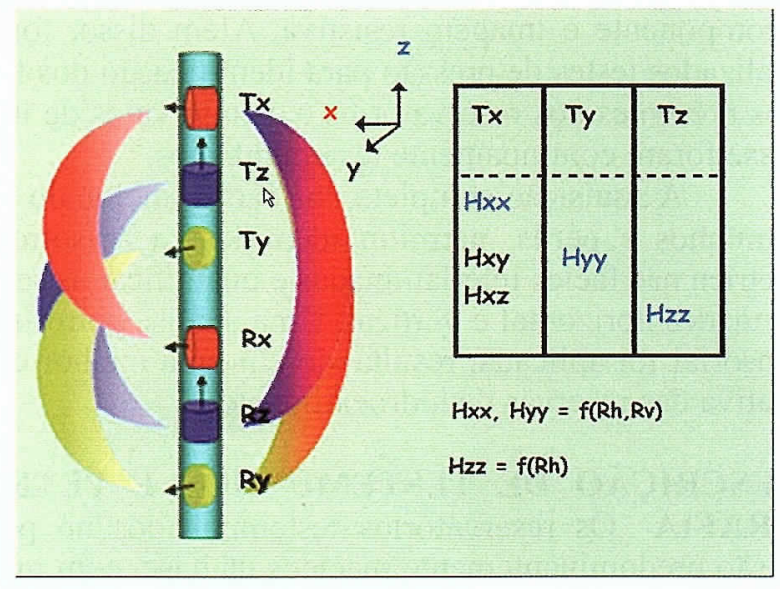

Figura 3 - Arranjo da ferramenta de indução multicomponente (modificado de Yu et al. 2001). 


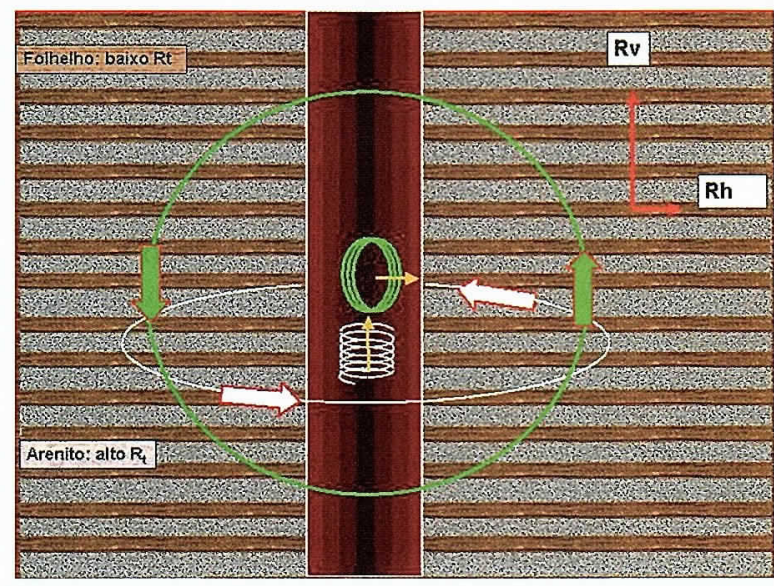

Figura 4-Resposta da ferramenta 3DEX em poços verticais (Kriegshäuser et al., 2000).

lado, os dados obtidos pelas componentes Hxx e Hyy são função tanto de Rv quanto de Rh sendo, portanto, essenciais para detectar a anisotropia de resistividade. Segundo Yu et al. (2001), essas medidas fornecem os dados necessários para estimar as resistividades horizontal e vertical de formações que apresentam simetria VTI, permitindo a determinação da resistividade real das lâminas de areia e consequentemente uma melhor quantificação da saturação de hidrocarbonetos em reservatórios deste tipo.

ESTUDO DE CASO: POÇO A O poço A, localizado em uma área explotatória ao norte da Bacia de Campos, foi perfurado com o objetivo de verificar o espessamento, sugerido na sísmica, dos reservatórios turbidíticos miocênicos da Formação Carapebus e verificar também a posição do contato óleo/ água na área.

O poço, com geometria vertical, foi perfurado em lâmina d'água superior a $1000 \mathrm{~m}$, mesa rotativa de $26 \mathrm{~m}$ e com lama base água. Foram corridos os perfis convencionais, tais como, raios gama, resistividade, densidade e neutrão, adicionalmente perfis especiais como ressonância magnética, perfil de indução multicomponente e imagem resistiva. Além disso, foram realizados testes de pressão para identificação dos fluidos presentes nos reservatórios e os intervalos de interesse foram continuamente testemunhados.

A aquisição completa dos dados, incluindo testemunhos e perfis, permitiu identificar a anisotropia elétrica nas fácies interlaminadas e quantificar as resistividades horizontal e vertical. Uma análise petrofísica tensorial foi aplicada, resultando em uma melhor estimativa das reservas de hidrocarbonetos.

DESCRIÇÃO DE TESTEMUNHOS E PETROGRAFIA Os reservatórios testemunhados no poço A são predominantemente maciços na base, com razão areia-argila elevada (acima de 85\%) gradando para sequências interlaminadas de areias e folhelhos na porção superior, interpretados como depósitos de overbank. Os arenitos são finos a muito finos, arredondados, bem selecionados e friáveis, com baixo volume total de argilas
$(0,5 \%)$ e portadores de hidrocarbonetos. Em geral, as porosidades e permeabilidades são superiores a $30 \%$ e $1000 \mathrm{mD}$. As análises petrográficas mostram tratar-se de arcósios a subarcósios, com a presença de K-feldspato, plagioclásio e baixo teor de fragmentos de rocha. Apresentam porosidade predominantemente intergranular e são localmente cimentados por calcita.

DADOS DE PRÉ-TESTES Os registros de pressão dos reservatórios estão sintetizados no gráfico de gradiente de pressão intervalar mostrado na figura 5. $\mathrm{O}$ intervalo analisado representa os objetivos principais do poço. Conforme observado na figura, os pontos estão alinhados definindo um gradiente equivalente a um fluido de densidade igual a $0,8 \mathrm{~g} / \mathrm{cc}$. Os testes de formação realizados em alguns intervalos confirmam a presença de óleo nestas zonas. A zona localizada abaixo dos reservatórios de interesse encontra-se saturada com água, conforme indicação dos perfis de resistividade e corroborado pelo resultado dos testes de formação efetuados no intervalo. Não foi constatado em perfil um contato óleo/água na região do poço.

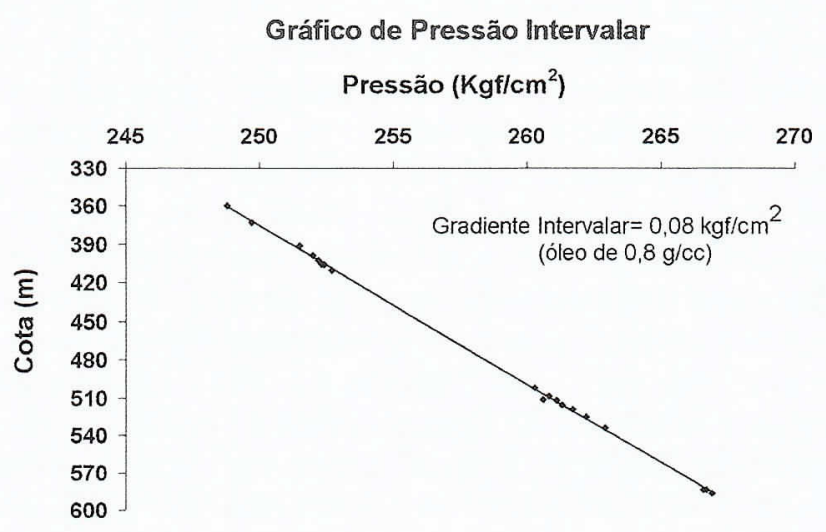

Figura 5 - Dados de pressão do poço A. Pontos correspondem a um gradiente equivalente ao óleo. As cotas tiveram a milhar suprimida.

ANÁLISE PETROFÍSICA CONVENCIONAL A análise quantitativa de perfis foi feita através do modelo determinístico, utilizando o programa Interactive Petrophysics da Schlumberger.

O primeiro passo consistiu na identificação das zonas de interesse. Os intervalos 1 e 2 (Figs. 6 e 7) foram diferenciados porque representam zonas produtoras distintas. O crossover dos perfis de densidade e neutrão, utilizado como indicador da presença de arenitos, não foi eficiente na identificação visual dos reservatórios. Por isso, para uma melhor visualização, foi utilizado como discriminante a curva DRDN, conforme equação 4:

$$
D R D N=\left(\frac{R H O B-2}{0,05}\right)-\left(\frac{0,45-N P H I}{0,03}\right)
$$




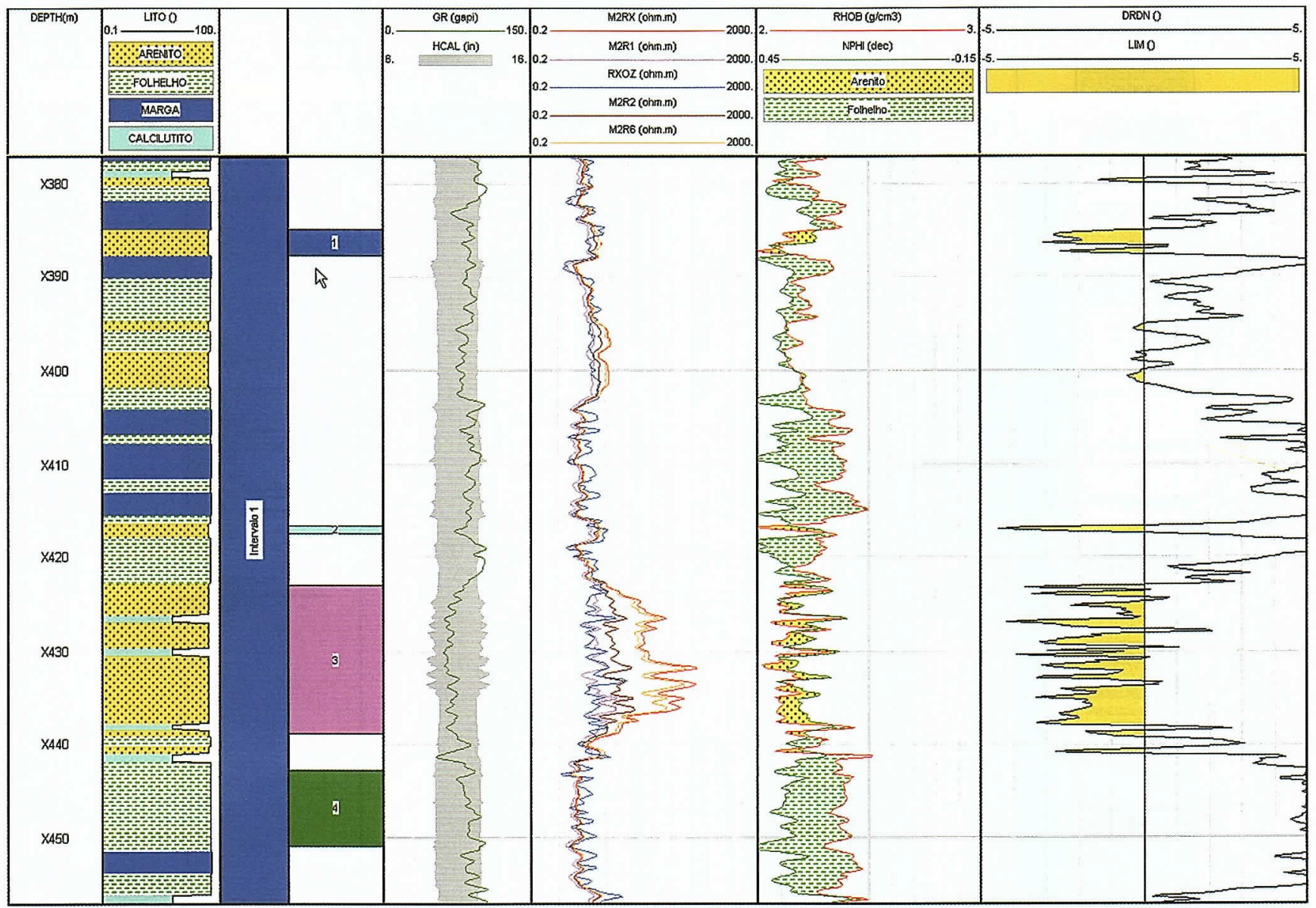

Figura 6 - Layout do zoneamento obtido através da curva DRDN. No track mais a direita, é possivel identificar os reservatórios pelo sombreado amarelo. Track 1: profundidade; track 2: litologia descrita no campo; tracks 3 e 4: zoneamentos; track 5: caliper e gamma ray; track 6: resistividades; track 7: par densidade/neutrão; track 8: curva de DRDN. As profundidades tiveram a milhar suprimida.

em que valores negativos representam os arenitos e os positivos, os folhelhos e margas.

Uma vez identificados os reservatórios, foi feito um zoneamento em função dos dados pré-existentes fornecidos pela equipe responsável pelo campo Gabriel. Os intervalos 1 (X370m a X464m), superior, e 2, inferior (X502m a X596m) são preenchidos por arenitos miocênicos. Os reservatórios situados abaixo de X605m, também miocênicos, foram descartados da avaliação por serem portadores de água, fato confirmado pelas curvas de resistividade e pelos registros de pressão.

No intervalo 1 (Fig. 6) foram identificadas três zonas de reservatórios, sendo as duas primeiras pouco espessas, com as curvas de densidade e neutrão indicando alto conteúdo de folhelho e resistividades baixas. A zona 3, por outro lado, compreende arenitos mais limpos, com raios gama baixos e valores de resistividade na ordem de dezenas de ohm.m. A zona 4 corresponde ao folhelho adjacente, utilizado para calibração da curva de volume de argila (Vsh).

No intervalo 2 (Fig. 7) foram identificadas três zonas $(5,6$ e 7$)$, em que a zona 5 e o topo da 6 , com hidrocarbonetos, não foram facilmente identificadas a partir dos perfis convencionais. Os valores de resistividade são baixos e as curvas de densidade e neutrão mostram alto conteúdo de folhelho. No entanto, os registros de pressão e, posteriormente, os testes de formação, confirmaram a presença de óleo nestes intervalos. De maneira similar ao intervalo 1 , a zona 8 representa o folhelho adjacente aos reservatórios do intervalo 2 .

Uma vez identificados os reservatórios, foram calculadas as porosidades totais a partir dos perfis de densidade (PhiDen) e neutrão (PhiNeu).

A porosidade PhiDen foi estimada a partir de um valor de densidade de matriz de $2,68 \mathrm{~g} / \mathrm{cc}$, obtido pelo histograma das densidades de matriz aparente para os dois intervalos (Figs. 8 e 9). Este resultado é coerente com a matriz da rocha que, embora quartzítica, apresenta cimentação carbonática, possivelmente com presença de concreções (Figs.10 e 11).

As porosidades obtidas pelos perfis de densidade e neutrão foram bastante semelhantes nos intervalos maciços, como p.ex, nas zonas 3 e na base da zona 6 (Fig. 12). A separação observada em alguns trechos, principalmente na porção superior da zona 6 , fornece uma indicação do aumento progressivo da argilosidade reservatório acima, uma vez que as porosidades neutrô- 

indução multicomponente

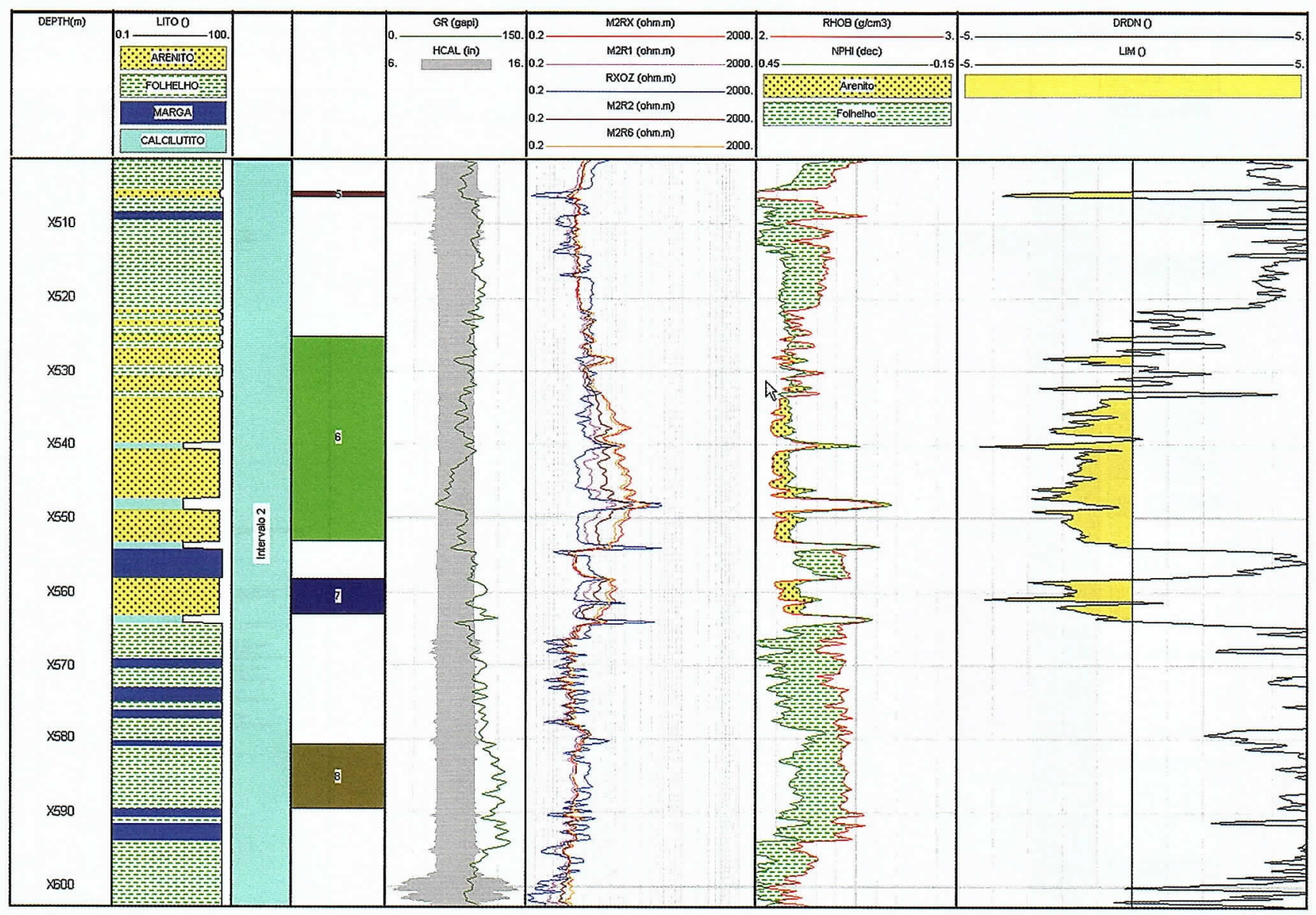

Figura 7 - Layout do zoneamento obtido através da curva DRDN. No track mais a direita, é possivel identificar os reservatórios pelo sombreado amarelo. Track 1: profundidade; track 2: litologia descrita no campo; tracks 3 e 4: zoneamentos; track 5: caliper e gamma ray; track 6: resistividades; track 7: par densidade/neutrão; track 8: curva de DRDN. As profundidades tiveram a milhar suprimida.

nicas são muito afetadas pela presença de absorvedores presentes nas micas e/ou argilas, superestimando-a.

O cálculo de volume de argila foi feito utilizando uma combinação dos perfis de raios gama e dos perfis de densidade e porosidade neutrônica. Os gráficos das figuras 13 e 14 sugerem que a argila predominante nas areias do intervalo 1 seja a estrutural ao passo que no intervalo 2 , especialmente na zona 6 , ocorre uma predominância de argila laminar. Uma vez que os pontos referentes a zona 7 eram pouco representativos, optou-se por considerar a argila estrutural como predominante, balizado no fato de que as curvas de densidade e neutrão apresentaram alguma separação.

Utilizou-se como resultado de argilosidade a curva VCL, mais otimista, uma vez que esta considera os valores mais baixos de cada um dos dois métodos. Optou-se por esta curva pelo fato do perfil de raios gama estar muito afetado pela radioatividade dos arenitos arcosianos do reservatório.

Os cálculos de saturação de água foram efetuados utilizando as equações de Archie (equação 5) ou Dual Water (equação 6), em função da argilosidade do reservatório.

$$
\frac{1}{R t}=\frac{\phi^{m}}{a} x \frac{S w^{n}}{R w}
$$

$$
\frac{1}{R t}=\frac{\phi^{m} x S w t^{n}}{a} x\left(\frac{1}{R w}+\frac{S w b}{S w t} x\left(\frac{1}{R w b}-\frac{1}{R w}\right)\right)
$$

em que:

$\mathrm{R} t=$ resistividade da formação;

$\phi=$ porosidade;

$\mathrm{m}=$ expoente de cimentação;

$\mathrm{a}=$ fator de tortuosidade;

$\mathrm{n}=$ expoente de saturação;

$\mathrm{Sw}$ = saturação de água;

$\mathrm{Rw}=$ resistividade da água de formação;

Swb =saturação da água da argila;

$\mathrm{Rwb}=$ resistividade da água da argila.

O parâmetro $\mathrm{m}$ foi obtido a partir do Picket Plot (Fig. 15) feito num reservatório com água abaixo do intervalo 2 e representa o gradiente do trend linear. $\mathrm{O}$ valor encontrado $(1,88)$ é coerente, uma vez que estas areias estão moderadamente cimentadas, conforme observado nas descrições de campo e de testemunho. O fator de tortuosidade " $a$ " e o expoente de saturação " $n$ ", também utilizados nas equações de saturação, foram os usuais ( 1 e 2 , respectivamente).

O $R w$ utilizado para os reservatórios miocênicos foi de 0,09 ohm.m @ 75º (81.000 ppm NaCl), obtido 
RhoMatApp (gm/cc)

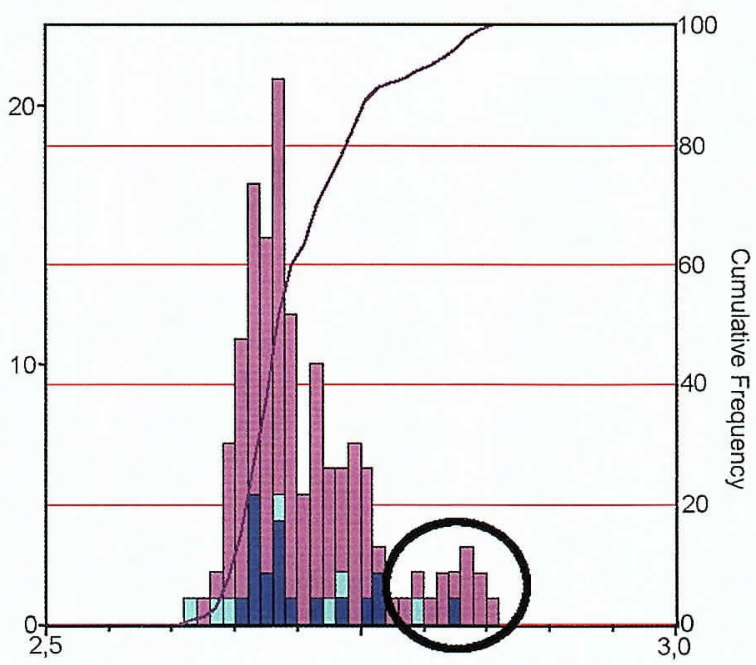

Figura 8 - Histograma de densidade de matriz no intervalo 1 . Optou-se pela moda $(2,68 \mathrm{~g} / \mathrm{cc})$, uma vez que a média $(2,70 \mathrm{~g} / \mathrm{cc})$ contempla os valores assinalados no circulo preto que, segundo a descrição de campo, correspondem a intervalos cimentados, tornando-a mais alta que a moda.

\section{RhoMatApp (gm/cc)}

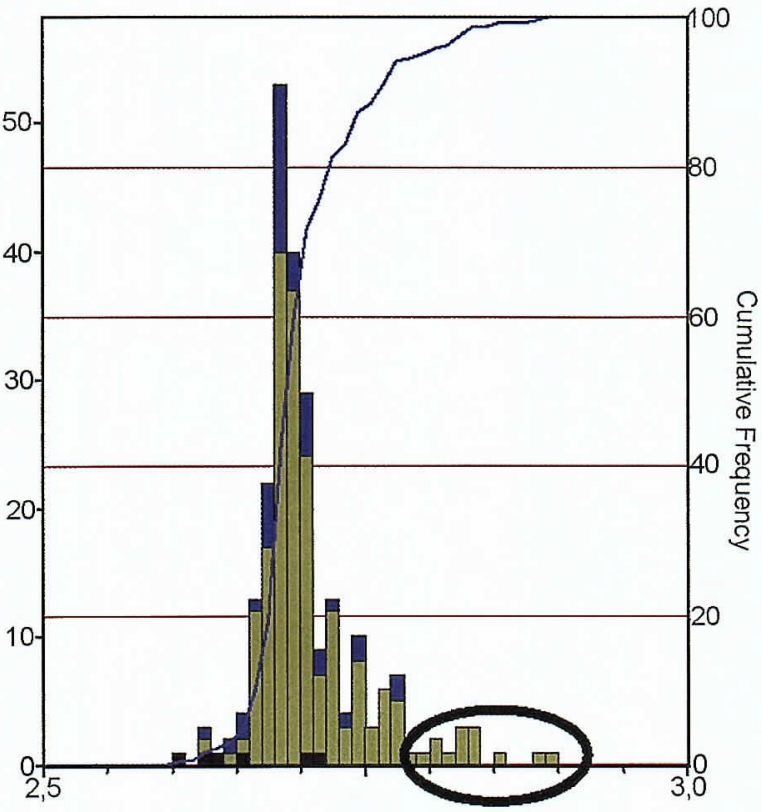

Figura 9 - Histograma de densidade de matriz no intervalo 2. Optou-se pela moda $(2,68 \mathrm{~g} / \mathrm{cc})$, uma vez que a média $(2.71 \mathrm{~g} / \mathrm{cc})$ contempla os valores assinalados em preto que, segundo a descrição de campo, correspondem a intervalos cimentados, tornando-a mais alta que a moda.

de uma amostra de água de um poço vizinho.

Nos reservatórios argilosos, a utilização do

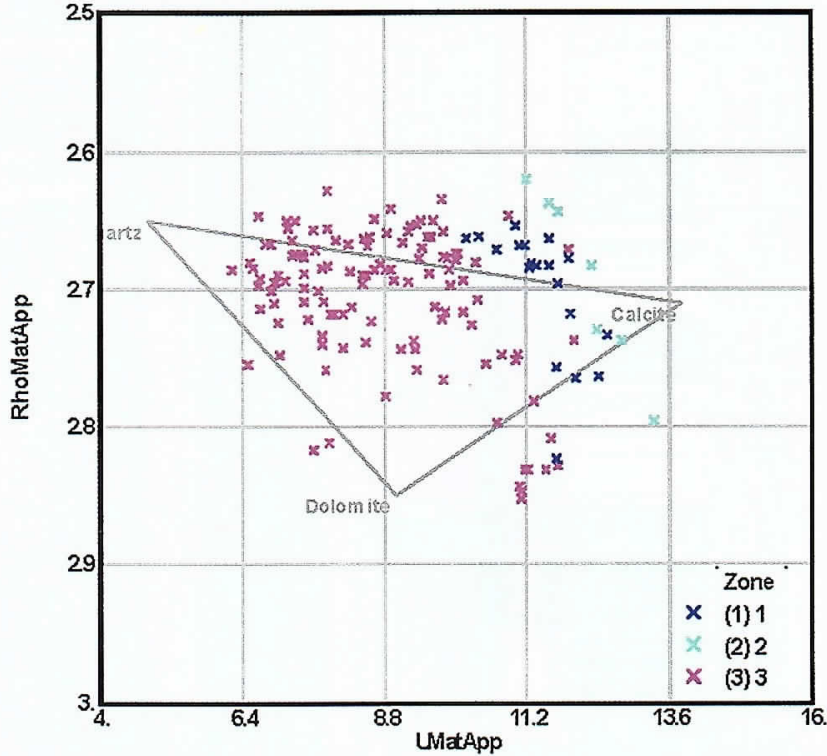

Figura 10 - Crossplot RhoMA $x$ Uma para intervalo 1, em que os pontos estão espalhados na linha arenito - calcita, indicando uma matriz quartzítica mas com alguma cimentação carbonática.

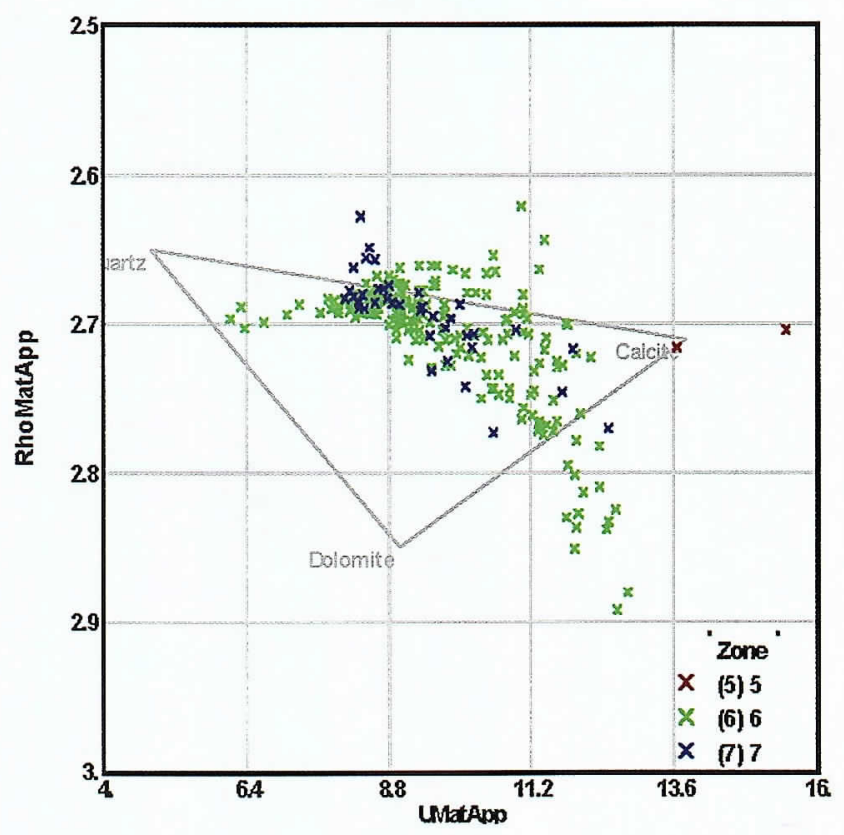

Figura 11 - Crossplot RhoMA x Uma para intervalo 2, em que os pontos estão espalhados na linha arenito - calcita, indicando uma matriz quartzítica mas com alguma cimentação carbonática.

modelo Dual Water é necessária porque ele desconta a contribuição da argila no cálculo da saturação de água, aumentando a saturação de óleo no reservatório. Para tal, é necessário calcular a porosidade total do folhelho ( $\phi$ tsh), resistividade da água da argila (Rwb) e a satura- 
Avaliação e caracterização de reservatórios laminados: comparação entre as ferramentas convencionais e o perfil de indução multicomponente

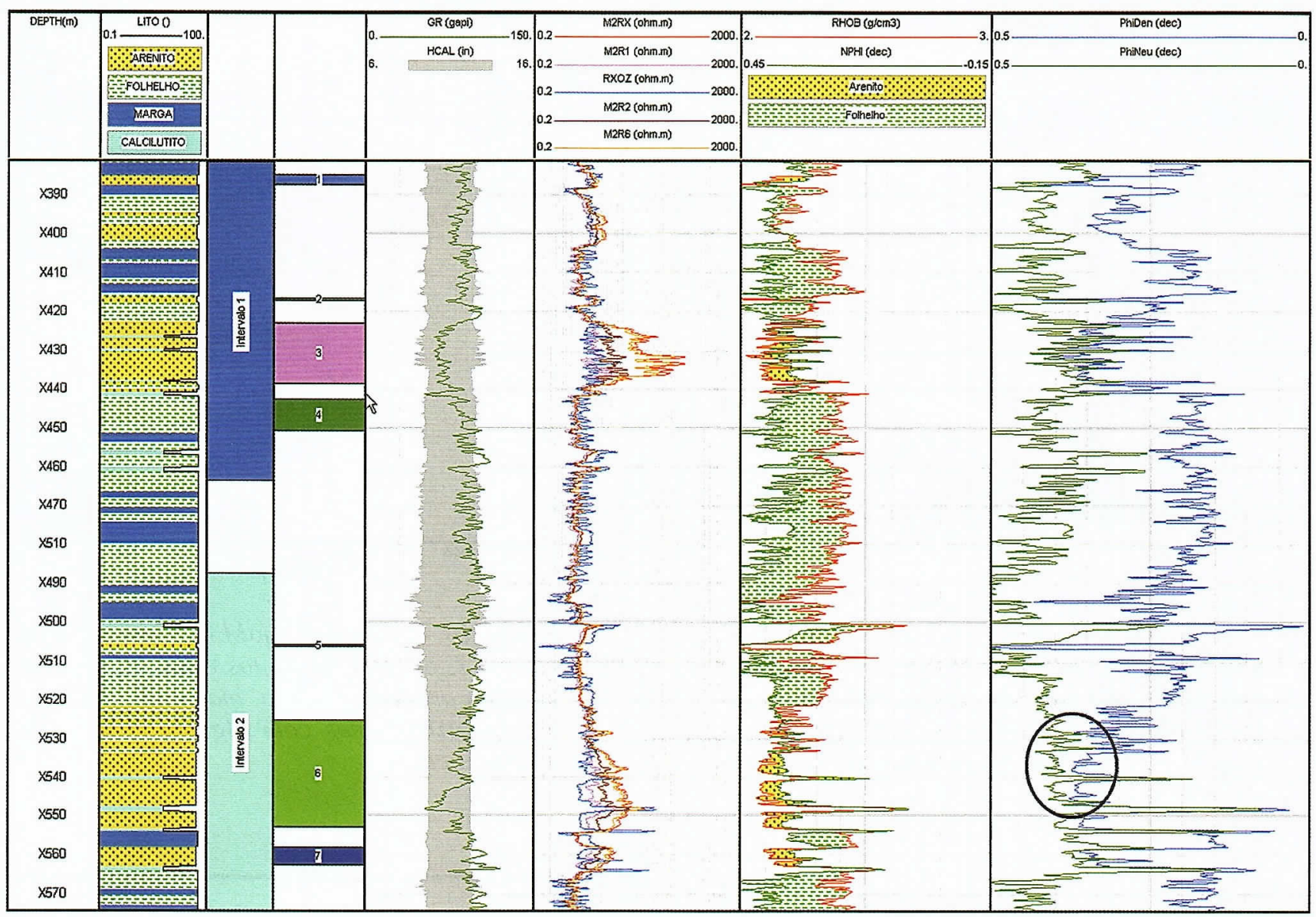

Figura 12 - Comparação entre as porosidades PhiDen e PhiNeu. Note que na zona 6 a porosidade neutrônica é maior, provavelmente em função da presença de argila neste trecho. As profundidades tiveram a milhar suprimida.

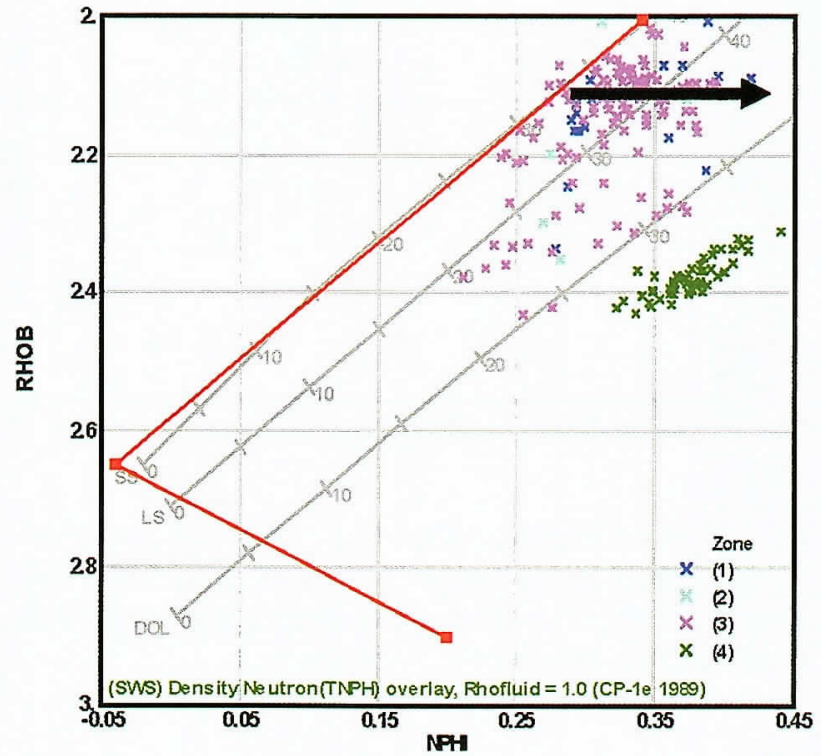

Figura 13 - Gráfico de RHOB x NPHI, sugerindo a presença de argila estrutural nos reservatórios do intervalo 1. Os pontos em verde representam o fothelho adjacente.

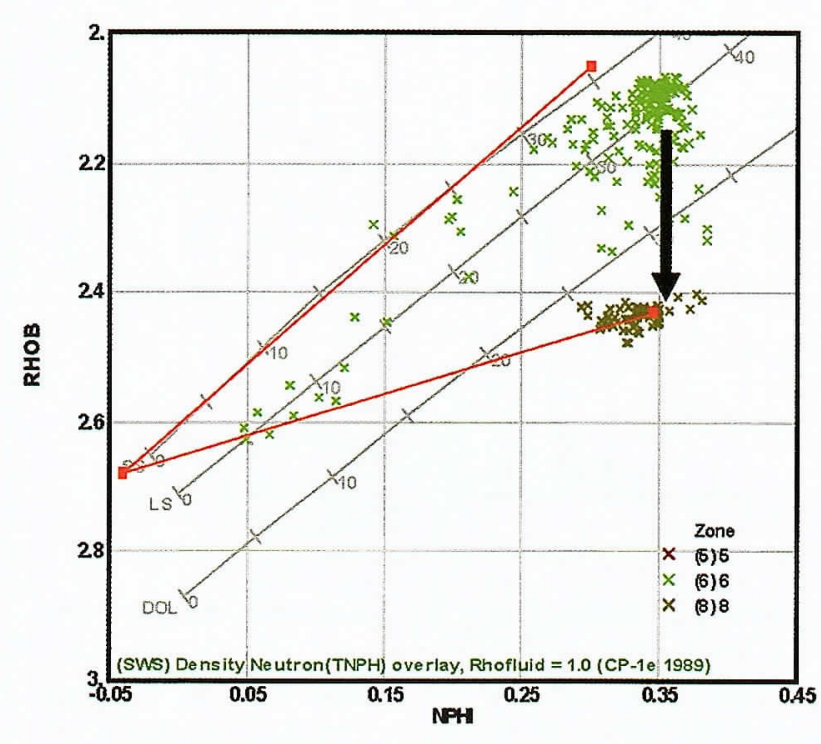

Figura 14 - Gráfico de RHOB x NPHI, sugerindo a presença de argila laminar nos reservatórios do intervalo 2. Os pontos em marrom representam o folhelho adjacente 
ção da água da argila (Swb).

A porosidade total do folhelho foi calculada a partir da equação 7 (Dewan, 1983):

$$
\phi t s h=\delta \times \phi d s h+(1-\delta) \phi n s h
$$

onde $\delta=0.5$ a $1, \phi$ dsh é a porosidade do folhelho obtida pelo perfil de densidade e $\phi$ nsh é a porosidade neutrônica do folhelho.

Considerando $\delta=1$, a porosidade total da argila será igual a porosidade PhiDen ( $\phi$ dsh) obtida numa zona de folhelho (Figs. 16 e 17).

A resistividade da água presente na argila (Rwb) foi calculada pela equação 8 (Dewan, 1983):

$$
R w b=R s h \times(\phi t s h)^{2}
$$

em que o Rsh corresponde a resistividade do folhelho adjacente.

Rsh foi obtida através de histograma da resistividade M2R9 (Figs. 18 e 19).

A saturação da água da argila foi obtida pela equação 9 (Dewan, 1983):

$$
S w b=\frac{V s h \times \phi t s h}{\phi t}
$$

A tabela 1 sumariza os parâmetros utilizados para os cálculos de porosidade efetiva e saturação de água para os dois intervalos. A figura 20 exibe um layout das curvas de volume de argila (conv:VCL) e

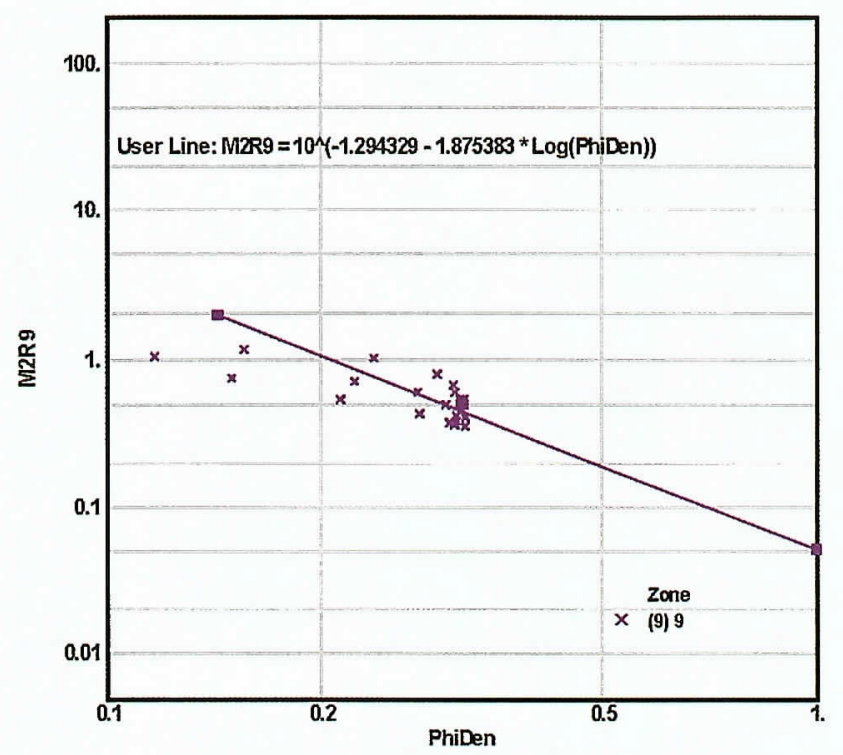

Figura 15 - "Picket plot" do reservatório com água situado abaixo do intervalo 2, onde são tirados o valor de $m(1,88)$ e o Rw (este previamente fixado, neste caso, para melhor ajuste do parâmetro $m$ ). saturação de água (conv:SW) para os reservatórios analisados. Paralelamente foram feitos ensaios de pressão capilar, em laboratório, para obtenção da saturação de água irredutível (Swi-m). A curva de saturação de água (Sw) obtida a partir dos perfis se ajustou bem aos resultados de Sw irredutível obtidos em laboratório pelo método da membrana, o que confere a esta uma boa calibração.

A totalização dos resultados para o poço está apresentada na tabela 2. Os valores de limite ("cut-off") utilizados foram os usuais: Vsh $=30 \%$; $\phi \mathrm{e}=12 \% \mathrm{e} \mathrm{Sw}$ $=50 \%$.

ANÁLISE PETROFÍSICA UTILIZANDO FERRAMENTAS ESPECIAIS (NMR, 3DEX E IMAGEM RESISTIVA) Nesta etapa, foram identificados 5 reservatórios (Fig. 21) a partir da análise conjunta dos perfis convencionais (raios gama, densidade, neutrão) e dos perfis de ressonância magnética (CMFF, CMRP, TCMR). O crossover dos perfis de densidade e neutrão, utilizado como indicador da presença de arenitos, não foi decisivo na identificação dos reservatórios, em função da argilosidade, que impacta na porosidade neutrônica, superestimando-a. O critério utilizado foi a identificação das zonas que apresentavam fluido livre representativo, colorido de azul na Figura 21. No track mais a direita, observa-se a distribuição dos tempos de relaxamento em que ocorre um deslocamento para a esquerda no reservatório 5, indicando uma mudança

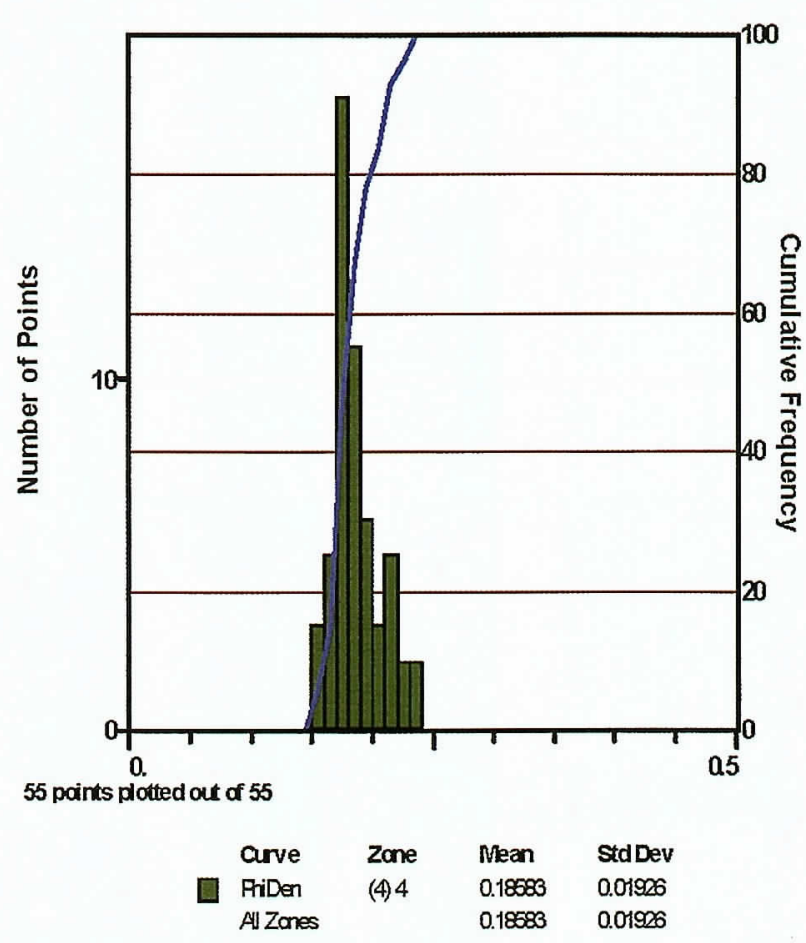

Figura 16 - Histograma da porosidade total do folhelho adjacente a partir da curva de densidade para o intervalo 1. Foi utilizada a média de 18\% como porosidade ( $\varphi$ tsh). 


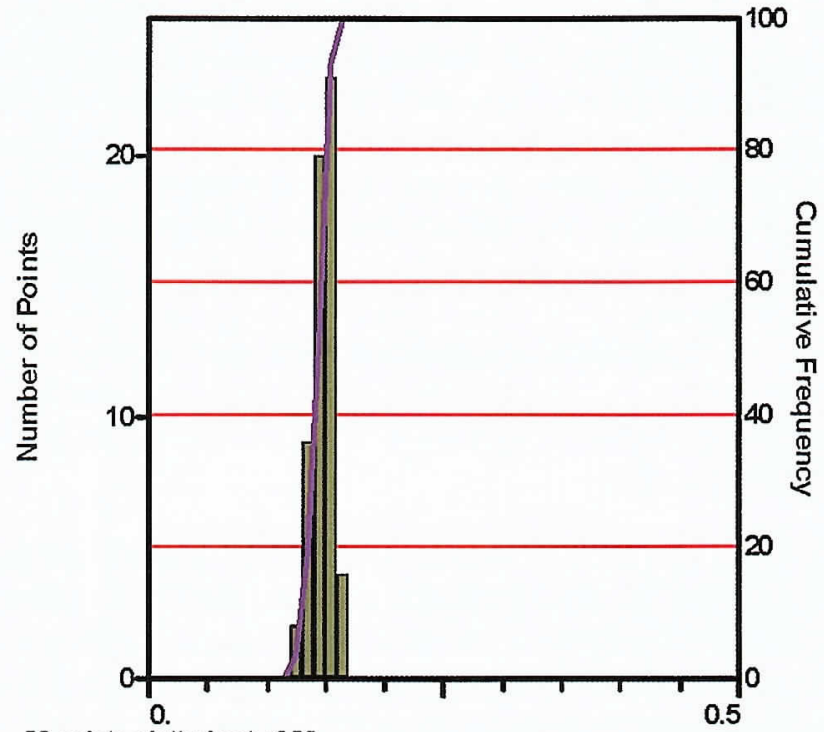

58 points plotted out of 58

$\begin{array}{llll}\text { Curve } & \text { Zone } & \text { Mlean } & \text { Std Dev } \\ \square \text { PtiDen } & (8) 8 & 0.1487 & 0.00959 \\ \text { All Zones } & & 0.1487 & 0.00959\end{array}$

Figura 17 - Histograma da porosidade total do folhelho adjacente a partir da curva de densidade para o intervalo 2. Foi utilizada a média de 15\% como porosidade ( $\varphi$ tsh).

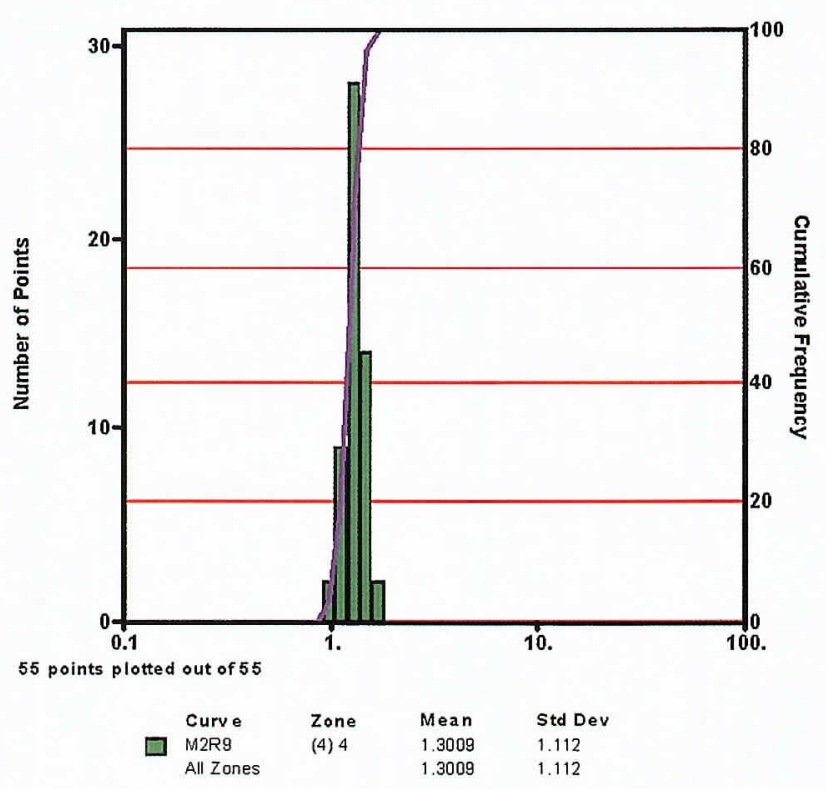

Figura 18 - Histograma da resistividade do folhelho adjacente para o intervalo 1. Foi utilizada a média de 1,30 ohm.m como resistividade (Rsh).

de fluido. Este dado corrobora o resultado dos registros de pressão e dos testes de formação que apontavam a água como fluido dominante nos reservatório abaixo de $\mathrm{X} 605 \mathrm{~m}$.

Um terceiro zoneamento foi realizado utilizando, desta vez, as resistividades horizontal e vertical da

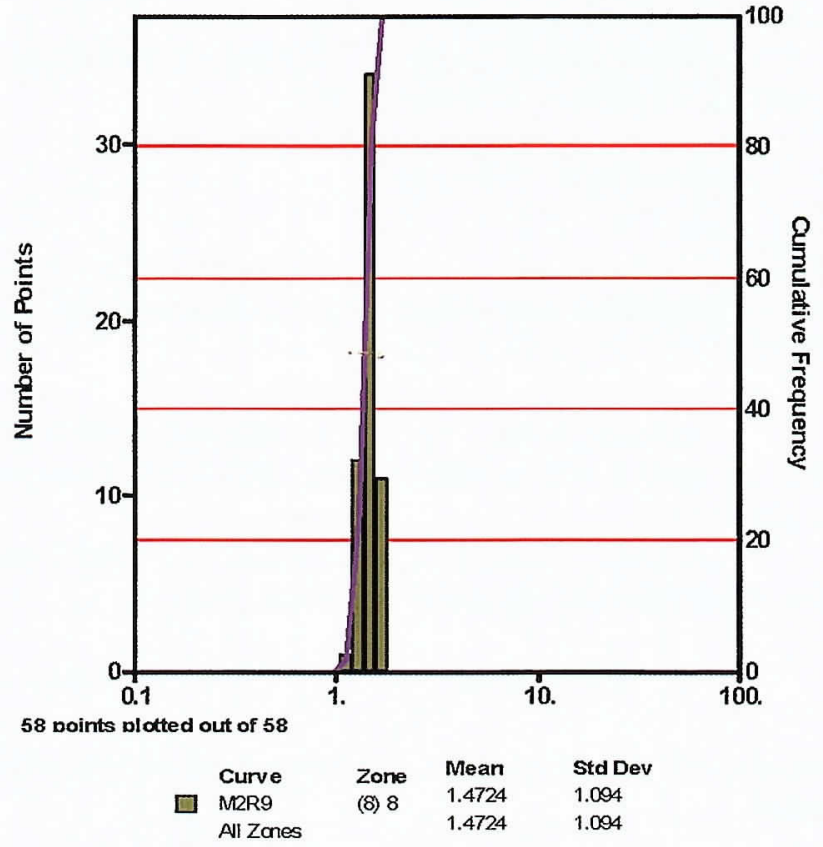

Figura 19 - Histograma da resistividade do folhetho adjacente para o intervalo 2. Foi utilizada a média de 1,47 ohm.m como resistividade (Rsh).

ferramenta de indução multicomponente (3DEX). A partir da anisotropia calculada pela "equação (1)" foi possível reconhecer os reservatórios laminados, anteriormente mascarados pelos perfis convencionais.

Foram identificados 7 intervalos (Fig. 22), sendo as zonas 3,6 e 7 isotrópicas, somente individualizadas para fins de totalização.

A zona 1, inicialmente caracterizada a partir do crossover densidade/neutrão, teve seu "net gross" aumentado após a obtenção dos perfis de ressonância magnética e de indução multi-componente. A anisotropia sozinha não é conclusiva quanto à litologia, mas a presença de fluido livre apontado no perfil de ressonância magnética forneceu confiabilidade a interpretação de que o intervalo era composto por uma intercalação folhelho/arenito com óleo, possivelmente mais cimentado na porção superior. $\mathrm{O}$ testemunho não recobre $\mathrm{o}$ intervalo por inteiro, mas foi descrito como interlaminado folhelho/arenito na porção inferior da zona 1.

Assim como na zona 1, a zona 2 também teve seu "net gross" aumentado, no entanto os $2 \mathrm{~m}$ superiores do intervalo, embora apresentem anisotropia, não contêm fluido livre, o que nos permite inferir que não se trata de rocha reservatório. Todavia, o restante do intervalo apresenta anisotropia e fluido livre e, embora não testemunhado, foi avaliado como um reservatório interlaminado arenito/folhelho. O final da zona 2 coincide com o início da zona 3 , maciça, individualizada pelo par densidade/neutrão. Esta interpretação é coerente com o modelo deposicional aceito para os turbiditos da bacia de Campos, normalmente compostos de arenitos maciços na base gradando para porções interlaminadas 
Tabela 1 - Parâmetros utilizados no cálculo de porosidade efetiva e de saturação de água nos dois intervalos com base nos perfis convencionais. Vale destacar que as zonas 4 e 8 são folhelhos e por isso, não computadas nestes cálculos.

\begin{tabular}{c|c|c|c|c|c|c}
\hline & $\begin{array}{c}\text { Densidade de } \\
\text { matriz (g/cc) }\end{array}$ & $\begin{array}{l}\text { Modelo de } \\
\text { porosidade }\end{array}$ & Vsh & $\begin{array}{c}\text { Equação de } \\
\text { Saturação }\end{array}$ & $\begin{array}{c}\text { PhiT clay } \\
(\%)\end{array}$ & Rsh \\
\hline Zona 1 & 2,68 & Densidade & VCL & Dual Water & 0,18 & 0,04 \\
\hline Zona 2 & 2,68 & Densidade & VCL & Archie & - & - \\
\hline Zona 3 & 2,68 & Densidade & VCL & Archie & - & - \\
\hline Zona 5 & 2,68 & Densidade & VCL & Dual Water & 0,15 & 0,03 \\
\hline Zona 6 & 2,68 & Densidade & VCL & Dual Water & 0,15 & 0,03 \\
\hline Zona 7 & 2,68 & Densidade & VCL & Dual Water & 0,15 & 0,03 \\
\hline
\end{tabular}

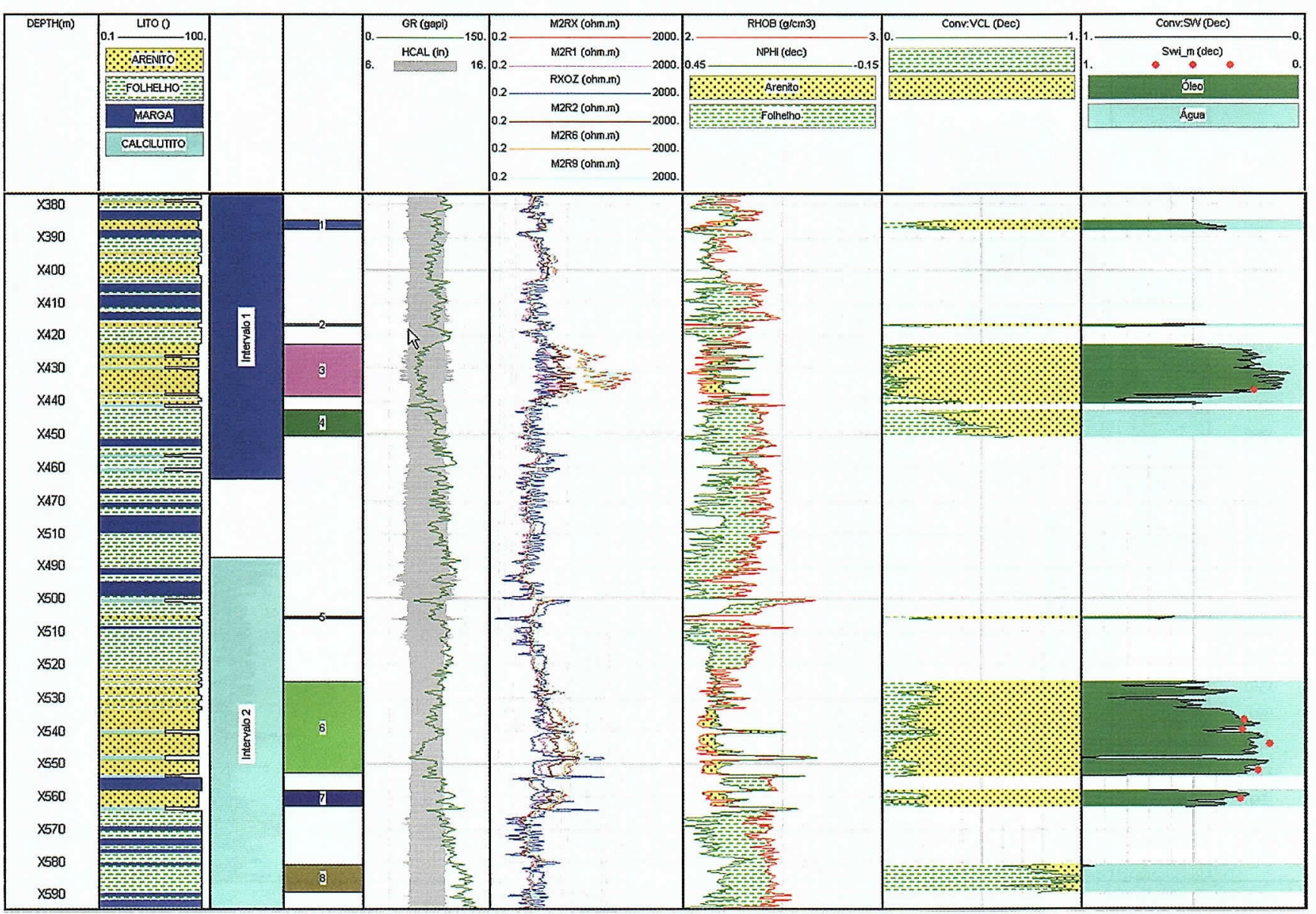

Figura 20 - Layout final obtido através dos perfis convencionais. Track 1: profundidade; track 2: litologia descrita no campo; tracks 3 e 4: zoneamentos; track 5: caliper e gamma ray; track 6: resistividades; track 7: par densidade/neutrão; track 8: curva de VCL; track 9: Sw. Os pontos em vermelho no track 9 correspondem aos valores obtidos pelo ensaio de dessaturação pelo método da membrana. As profundidades tiveram a milhar suprimida.

no topo.

A zona 4 não tinha sido individualizada pelos perfis convencionais e também não apresentou fluido livre na ressonância magnética. A anisotropia, neste caso, não é função da presença de óleo. O testemunho (Fig. 23) mostrou tratar-se de um intervalo folhelho/ arenito cimentado, fato que explica a resposta anisotró- pica do intervalo.

A zona 6 , individualizada pelos perfis convencionais, foi subdividida em duas quando utilizada a ferramenta de indução multi-componente. Um intervalo superior, anisotrópico (zona 5), descrito como interlaminado areia/folhelho (Fig. 24) e um inferior, isotrópico (zona 6), constituído por arenito maciço (Fig. 25), 
Avaliação e caracterização de reservatórios laminados: comparação entre as ferramentas convencionais e o perfil de indução multicomponente

Tabela 2 - Totalização com base nos perfis convencionais.

\begin{tabular}{c|c|c|c|c|c}
\hline & Topo $(\mathrm{m})$ & Base $(\mathrm{m})$ & Net pay $(\mathrm{m})$ & PHI $(\%)$ & SW (\%) \\
\hline Zona 1 & $\mathrm{X} 384,91$ & $\mathrm{X} 387,80$ & 2,13 & 33,4 & 44,1 \\
\hline Zona 2 & $\mathrm{X} 416,61$ & $\mathrm{X} 417,52$ & 0,46 & 38,4 & 46,2 \\
\hline Zona 3 & $\mathrm{X} 423,01$ & $\mathrm{X} 440,84$ & 15,32 & 32,6 & 22,3 \\
\hline Zona 5 & $\mathrm{X} 505,76$ & $\mathrm{X} 506,52$ & 0,00 & - & - \\
\hline Zona 6 & $\mathrm{X} 525,27$ & $\mathrm{X} 553,92$ & 22,25 & 31,2 & 28,6 \\
\hline Zona 7 & $\mathrm{X} 558,19$ & $\mathrm{X} 563,06$ & 4,42 & 30,4 & 34,6 \\
\hline Total & & & 44,58 & 31,8 & 28,0
\end{tabular}

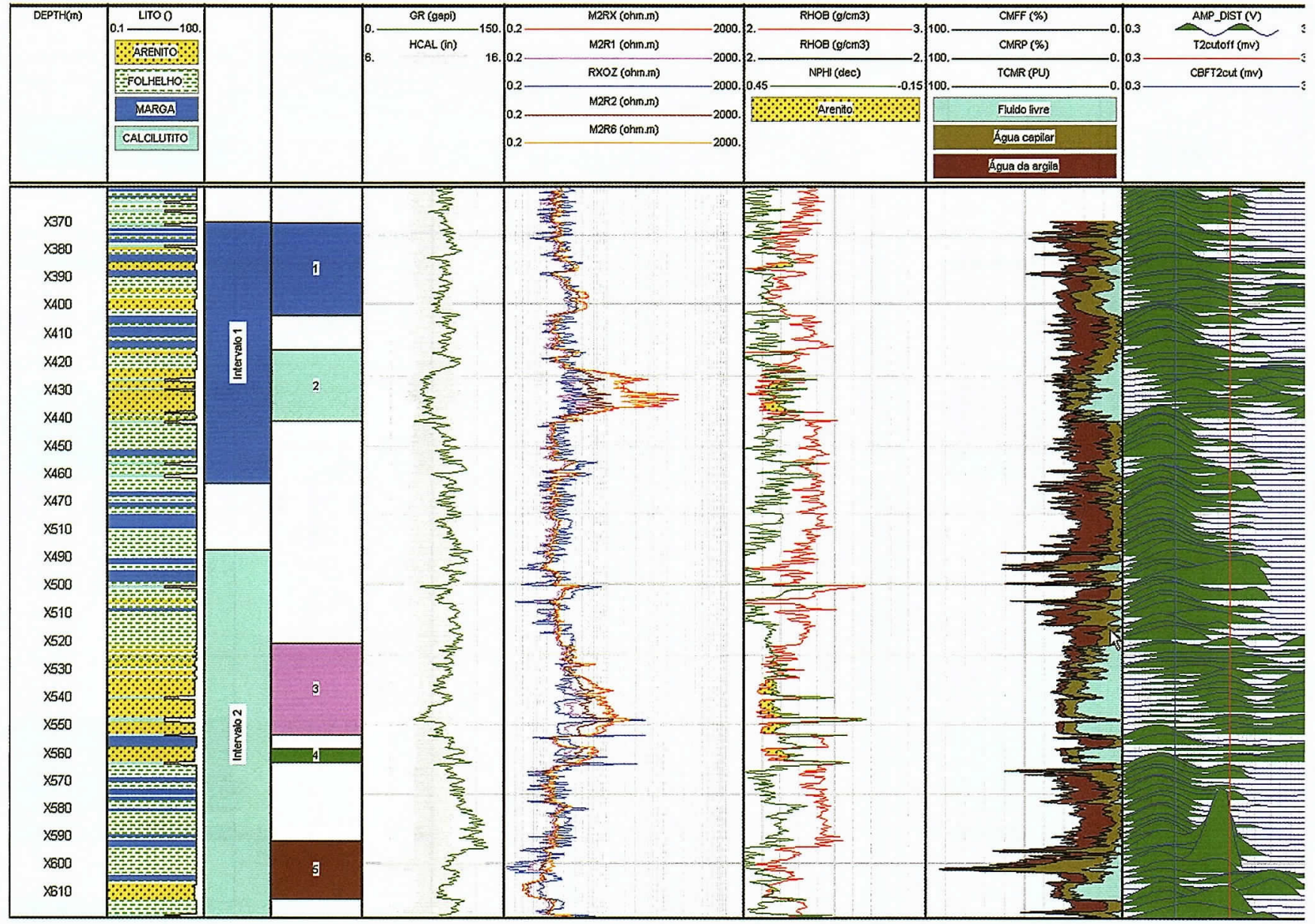

Figura 21 - Novo zoneamento utilizando as curvas de ressonância magnética, em que os reservatórios foram identificados pela presença de fluido livre, colorido de azul no track 8. Track 1: profundidade; track 2: litologia descrita no campo; track 3: intervalos 1 e 2, track 4: zoneamento NMR; track 5: caliper e gamma ray; track 6: resistividades; track 7: par densidade/neutrão; track 8: curvas de porosidade; track 9: distribuição dos tempos de relaxamento. As profundidades tiveram a milhar suprimida.

conforme descrição do testemunho. Vale a pena destacar que as zonas 5 e 6 foram reconhecidas pelo perfil de ressonância magnética (zona 3 ), mostrando que este fornece indicações precisas da presença de reservatório mesmo que não haja o crossover densidade/neutrão.

Os volumes de argila, as porosidades efetivas e as saturações de água foram recalculadas para os in- tervalos anisotrópicos (zonas 1,2 e 5) a fim de estimar o aumento de "net pay" com a utilização da ferramenta de indução multi-componente.

O volume de argila nestes reservatórios foi reinterpretado a partir da resistividade das lâminas de areia e da resistividade vertical, conforme equação 10 demonstrada por Mollison \& Mezzatesta (2000): 


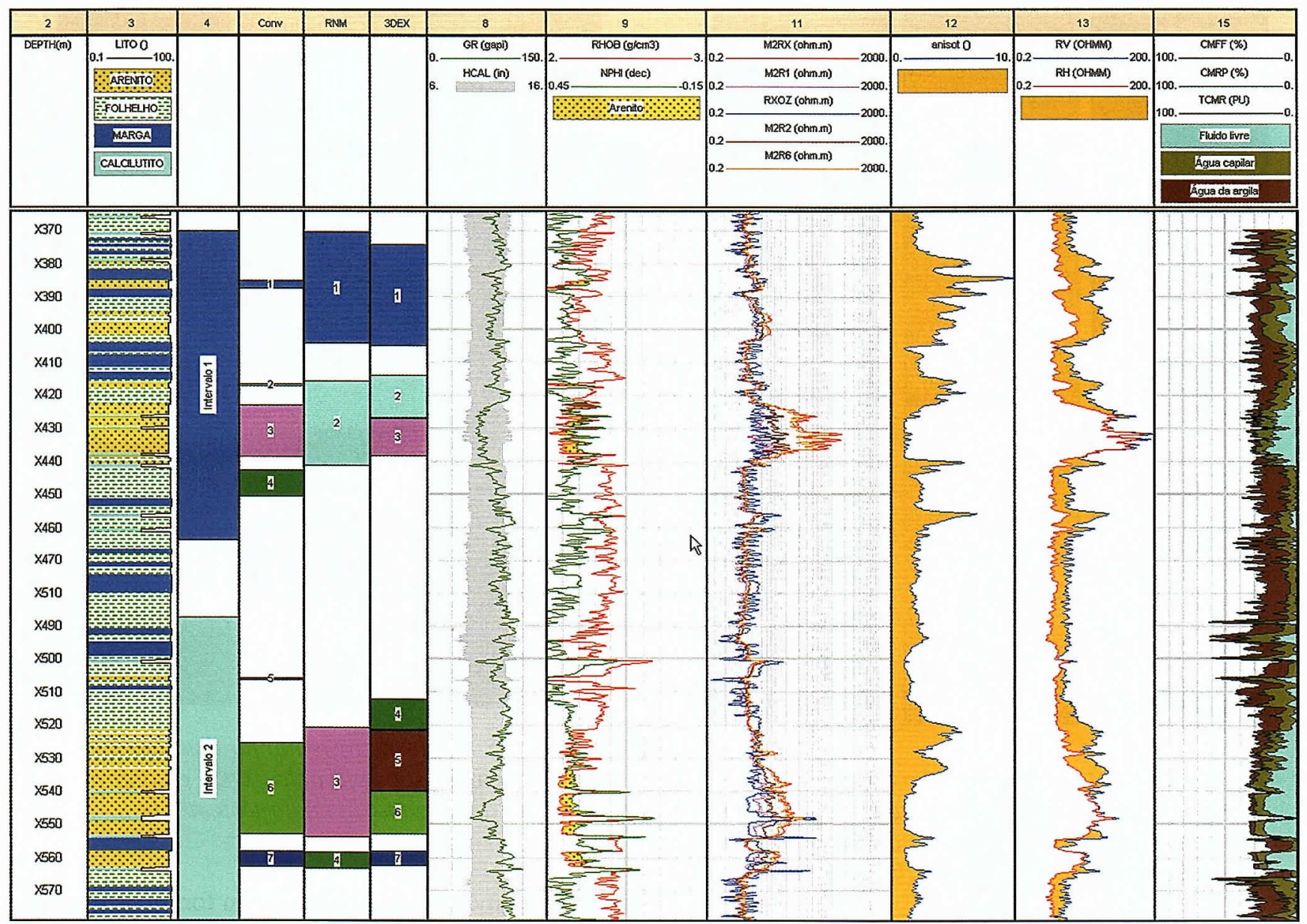

Figura 22 - Comparação entre os zoneamentos propostos a partir das três metodologias. Track 1: profundidade; track 2: litologia descrita no campo; track 3: intervalos 1 e 2, track 4: zoneamento par densidade/neutrão; track 5: zoneamento NMR; track 6: zoneamento 3DEX; track 7: caliper e gamma ray; track 8: par densidade/neutrão; track 9: resistividades; track 10: anisotropia, track 11: resistividades horizontal e vertical; track 12: curvas de porosidade. As profundidades tiveram a milhar suprimida.

$$
V s h=\frac{R s d-R v}{R s d-R s h}
$$

em que:

Vsh = volume de argila calculado através da ferramenta 3DEX,

Rsd = resistividade das lâminas de areia,

$\mathrm{Rv}=$ resistividade vertical obtida através do $3 \mathrm{DEX}$,

Rsh $=$ resistividade do folhelho, obtida através de um histograma de resistividade na zona do folhelho.

A resistividade das lâminas de areia (Rsd) é calculada através das resistividades horizontal e vertical (Mollison \& Mezzatesta 2000), de forma a eliminar a contribuição da argila, que atua diminuindo a resistividade real da formação com óleo (equação 11):

$$
R s d=R h\left(\frac{R v-R s h}{R h-R s h}\right)
$$

onde,
$\mathrm{Rh}=$ resistividade horizontal,

$\mathrm{Rv}=$ resistividade vertical,

Rsh $=$ resistividade do folhelho, obtida através de um histograma de resistividade na zona do folhelho.

A porosidade efetiva do intervalo laminado (Phie_L) foi calculada a partir da equação 12:

$$
\text { Phie_L } L=\frac{\phi t-(V s h \times \phi s h)}{1-V s h}
$$

onde,

$\phi \mathbf{t}=$ porosidade total (curva de PhiDen),

Vsh $=$ volume de argila,

$\phi s h=$ porosidade do folhelho (histograma de PhiDen na zona de folhelho).

A saturação de água nas zonas laminadas foi recalculada a partir da equação de Archie (equação 5), uma vez que a resistividade das lâminas de areia (Rsd) e a porosidade efetiva do intervalo laminado (Phie-L) já descontam a participação da argila no cálculo de satura- 

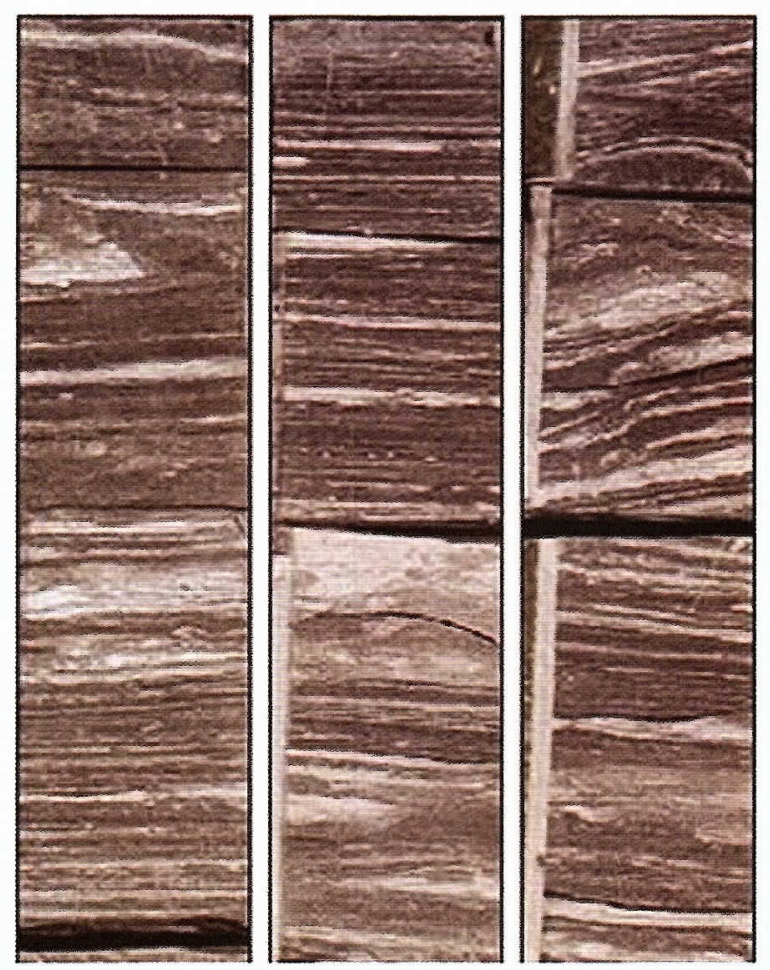

Figura 23 - Foto de testemunho da zona 4. Anisotropia causada pela intercalação de folhelho $e$ arenito cimentado. Intervalo considerado não reservatório, com ausência de fuido livre.
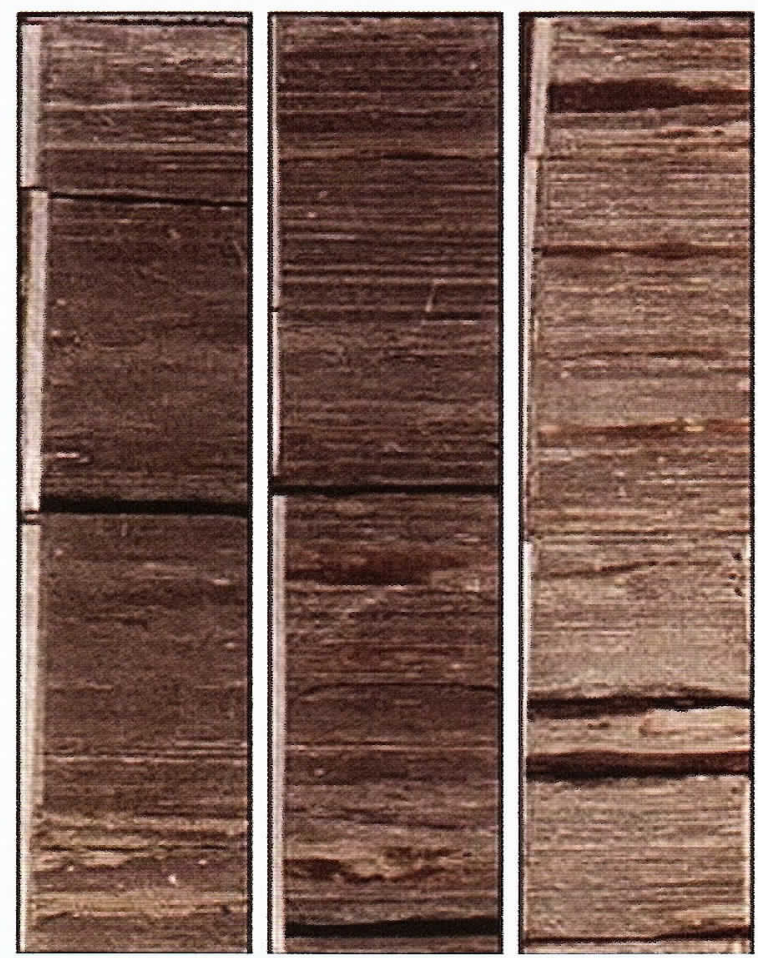

Figura 24 - Foto de testemunho da zona 5. Anisotropia causada pela sequência folhelho/arenito com óleo. Indicação de fluido livre confirmando a existência de um intervalo reservatório.
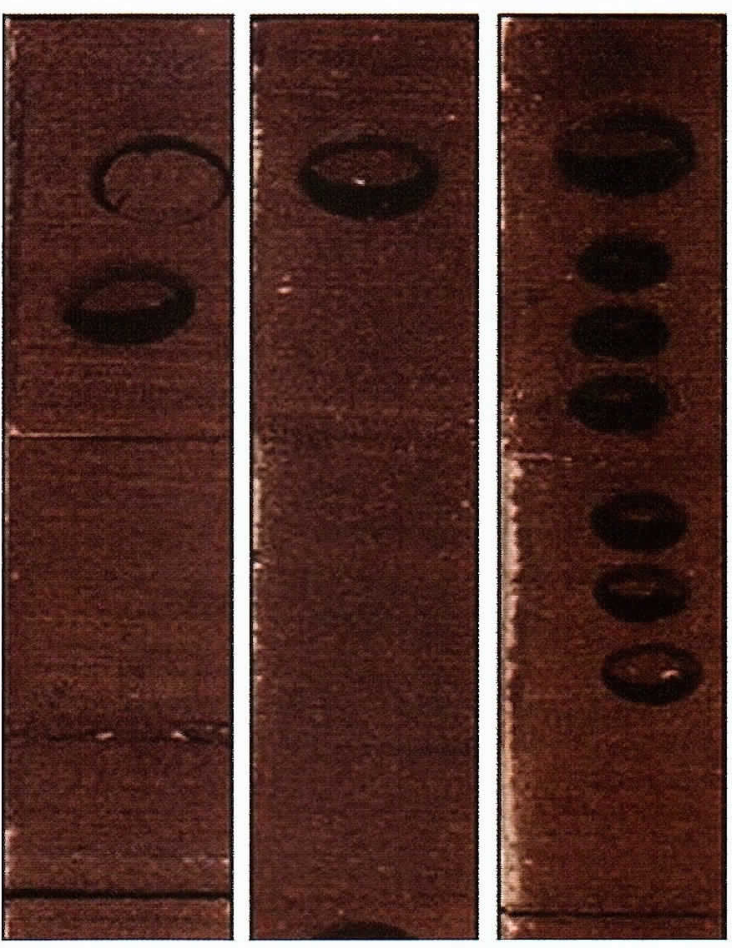

Figura 25 - Foto de testemunho da zona 6. Intervalo sem anisotropia pelo 3DEX e confirmado como arenito maciço pelo testemunho.

ção. Os parâmetros elétricos a, n e m foram os mesmos do cálculo através dos perfis convencionais.

A tabela 3 sumariza os parâmetros utilizados para os cálculos de porosidade efetiva e saturação de água para os dois intervalos. A figura 26 exibe um layout das curvas de volume de argila (Vsh-fim 3D), calculada a partir da equação 10 , e saturação de água (SWfim_3DEX) para os reservatórios. Vale destacar que as curvas de volume de argila e saturação de água calculadas a partir do 3DEX foram utilizadas somente nos intervalos laminados. Nas outras zonas foram mantidos os resultados obtidos através dos perfis convencionais. A curva de saturação de água (Sw) obtida a partir dos perfis se ajustou bem aos resultados de Sw irredutível obtidos em laboratório pelo método da membrana (pontos em vermelho), conferindo a esta uma boa calibração.

A totalização dos resultados para o poço está apresentada na tabela 4. Os valores de limite ("cut-off") utilizados foram os usuais para $\phi \mathrm{e}=12 \% \mathrm{e} \mathrm{Sw}=50 \%$. O "cut-off" para Vsh foi de $30 \%$ nas zonas maciças e em função da média de argila nas zonas laminadas.

Outro esforço que tem sido feito na tentativa de avaliar qualitativa e quantitativamente as seqüências laminadas de arenitos e folhelhos é utilizar perfis de imagens resistivas. As figuras 27 e 28 exibem as imagens obtidas para dois intervalos: X117m a X526m, que engloba as zonas 4 e 5 do 3DEX e X541m a X550m, que corresponde a zona 6 do 3DEX. As imagens, embora de alta resolução, somente diferenciaram o arenito maciço do interlaminado, mas não foram capazes de distinguir entre interlaminado folhelho/arenito e interlaminado 
Tabela 3 - Parâmetros utilizados no cálculo de porosidade efetiva e de saturação de água nos dois intervalos com base no perfil de indução multi-componente.

\begin{tabular}{c|c|c|c|c|c|c}
\hline & $\begin{array}{c}\text { Densidade de } \\
\text { matriz (g/cc) }\end{array}$ & $\begin{array}{c}\text { Modelo de } \\
\text { porosidade }\end{array}$ & Vsh & $\begin{array}{c}\text { Equação de } \\
\text { Saturação }\end{array}$ & $\begin{array}{c}\text { PhiT clay } \\
(\%)\end{array}$ & Rsh \\
\hline Zona 1 & 2,68 & Phie_L & Vsh & Archie & - & - \\
\hline Zona 2 & 2,68 & Phie_L & Vsh & Archie & - & - \\
\hline Zona 3 & 2,68 & Densidade & VCL & Archie & - & - \\
\hline Zona 4 & 2,68 & Densidade & Vsh & Archie & - & - \\
\hline Zona 5 & 2,68 & Phie_L & Vsh & Archie & - & - \\
\hline Zona 6 & 2,68 & Densidade & Vsh & Archie & - & - \\
\hline Zona 7 & 2,68 & Densidade & VCL & Dual Water & 0,15 & 0,03 \\
\hline
\end{tabular}

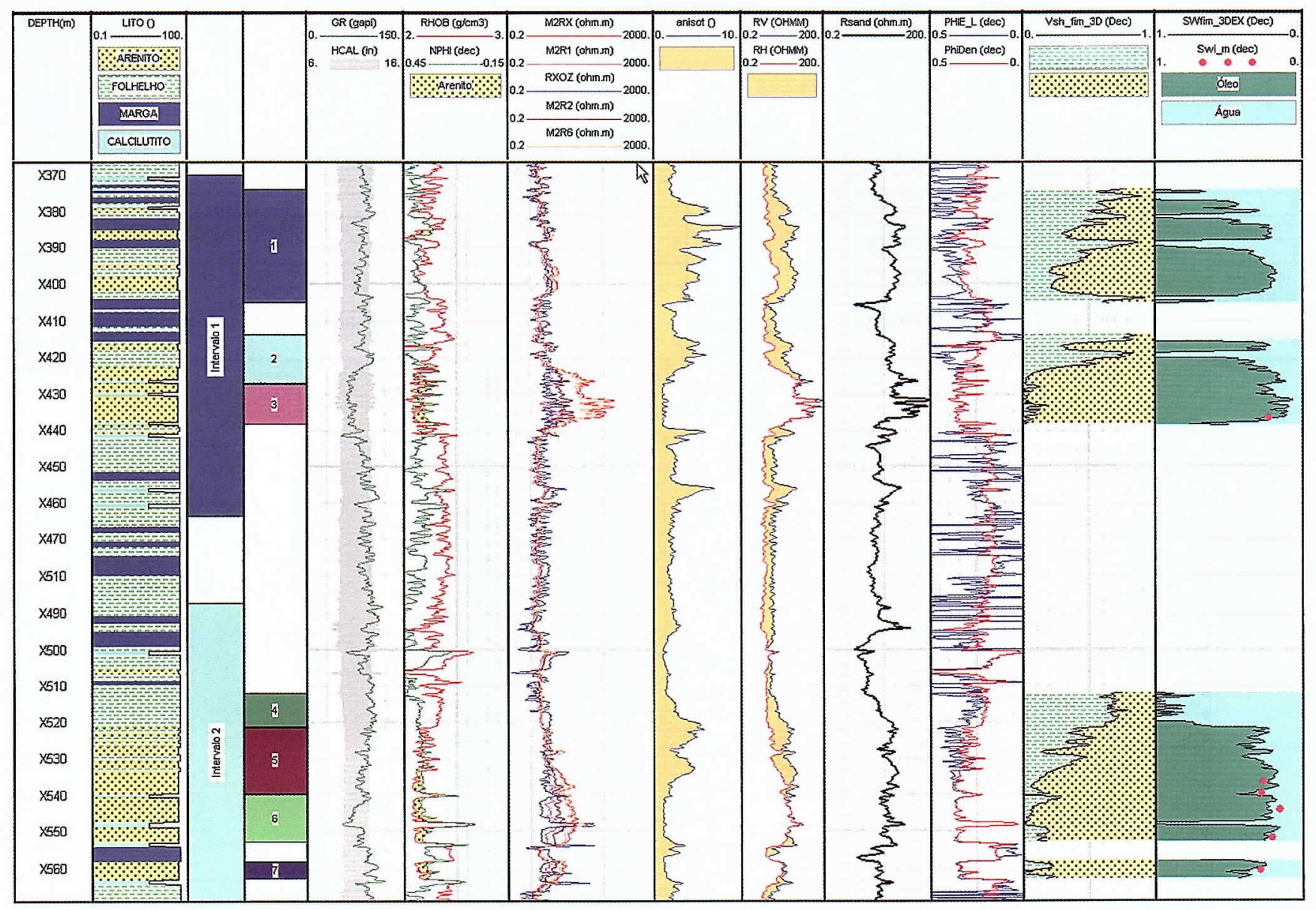

Figura 26 - Layout final obtido através do perfil 3DEX. Track 1: profundidade; track 2: litologia descrita no campo; tracks 3 e 4: zoneamentos; track 5: caliper e gamma ray; track 6: par densidade/neutrão; track 7: resistividades; track 8: anisotropia; track 9: Rv e Rh; track 10: Rsd; track 11: PhiDen e PHIE_L; track 12: Vsh; track 13: Sw. Os pontos em vermelho no track 12 correspondem aos valores obtidos pelo ensaio de dessaturação pelo método da membrana. As profundidades tiveram a milhar suprimida.

folhelho/arenito cimentado. A contagem de areia feita através da imagem foi a mais pessimista entre os três métodos, alcançando $24 \mathrm{~m}$ de "net pay" para o intervalo 2. É importante ressaltar que não foi possível ajustar uma boa calibração com a resistividade rasa, o que, se- gundo Yu et al. (2001), torna o perfil de imagem pouco eficiente. Além disso, esses autores também afirmam que os perfis de imagem não têm resolução vertical suficiente para seqüências finamente laminadas, ao contrário do indução multi-componente, cujas medidas 
Avaliação e caracterização de reservatórios laminados: comparação entre as ferramentas convencionais e o perfil de indução multicomponente

Tabela 4 - Totalização com base no perfil de indução multi-componente.

\begin{tabular}{c|c|c|c|c|c}
\hline & Topo $(\mathrm{m})$ & Base $(\mathrm{m})$ & "Net pay" $(\mathrm{m})$ & PHI (\%) & SW (\%) \\
\hline Zona 1 & X374,09 & X405,33 & 23,87 & 37,3 & 29,4 \\
\hline Zona 2 & $\mathrm{X} 413,86$ & $\mathrm{X} 427,27$ & 12,12 & 33,6 & 27,4 \\
\hline Zona 3 & $\mathrm{X} 427,27$ & $\mathrm{X} 438,55$ & 10.59 & 32,9 & 18,9 \\
\hline Zona 4 & $\mathrm{X} 512,16$ & $\mathrm{X} 521,46$ & - & - & 25,6 \\
\hline Zona 5 & $\mathrm{X} 521,46$ & $\mathrm{X} 539,90$ & 15,71 & 36,9 & 24,3 \\
\hline Zona 6 & $\mathrm{X} 539,90$ & $\mathrm{X} 553,16$ & 12,19 & 31,5 & 34,3 \\
\hline Zona 7 & $\mathrm{X} 558,19$ & $\mathrm{X} 562,91$ & 4,42 & 30,6 & 26,3 \\
\hline Total & & & 78,90 & 34,7 & 26 \\
\hline
\end{tabular}

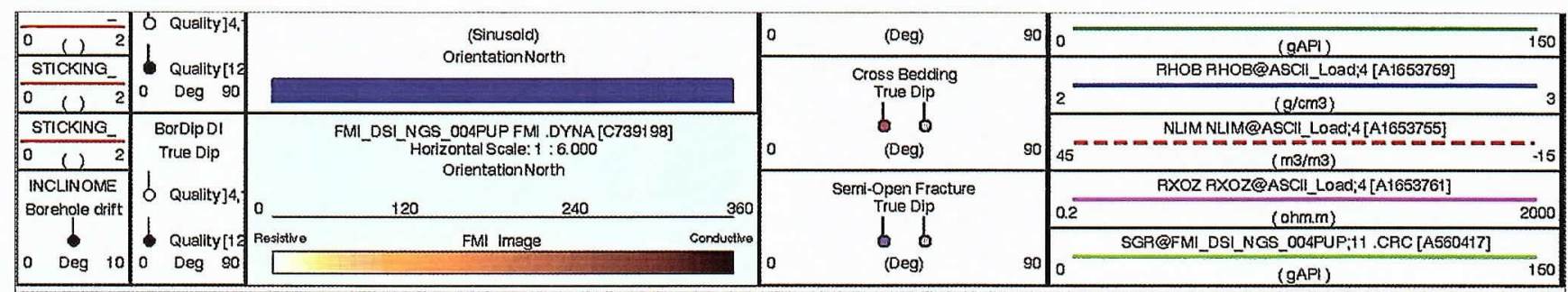

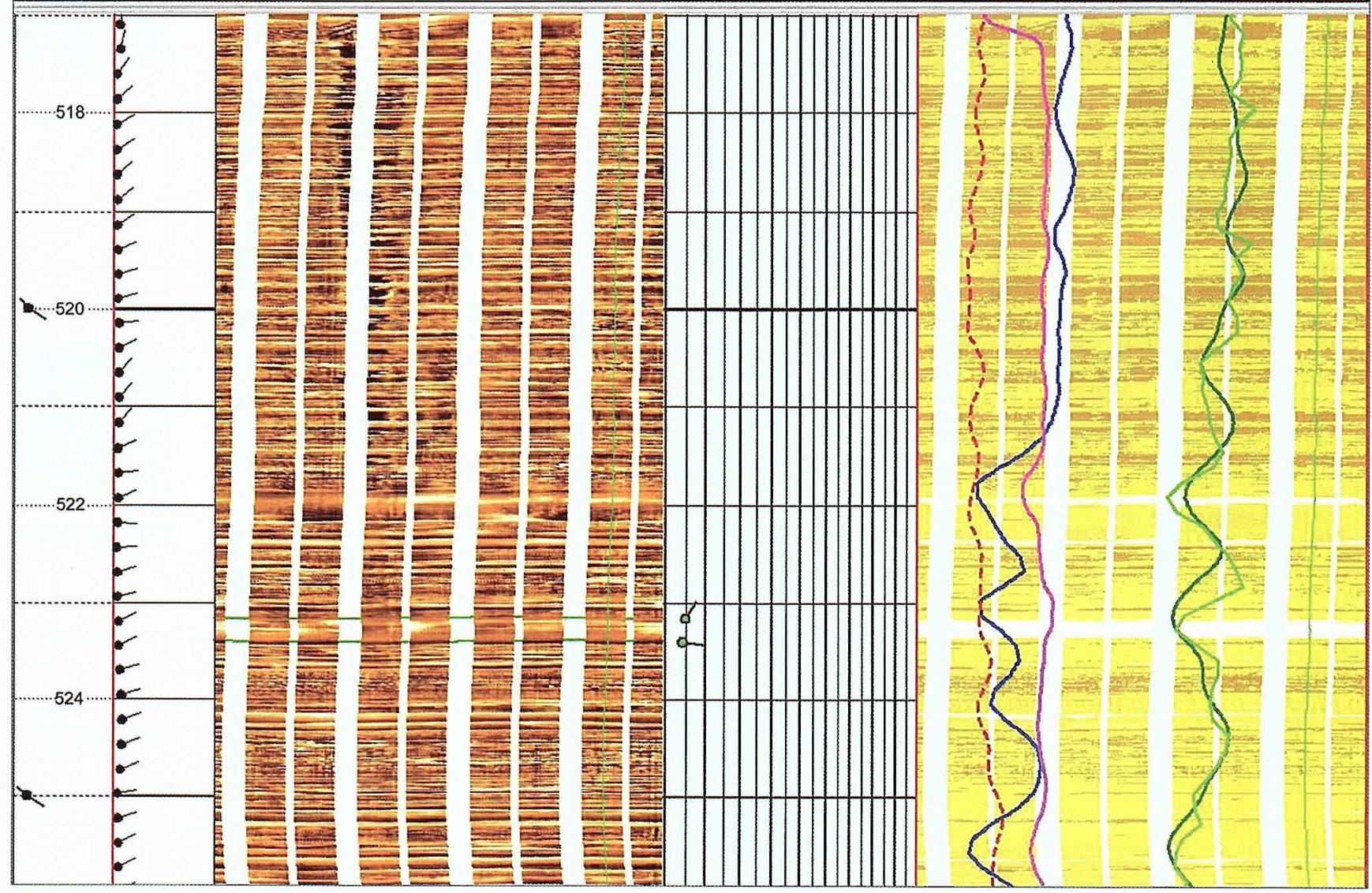

Figura 27 - Perfil de imagem resistiva correspondente ao intervalo X517m a X526m. A cimentação observada nos testemunho na porção superior não é notada na imagem. As profundidades tiveram a milhar suprimida. 
integram todas as resistividades de todas as camadas dentro de um intervalo.

COMPARAÇÃO ENTRE OS MÉTODOS Os resultados obtidos (Tab. 5) mostraram que a utilização do perfil de indução multi-componente foi capaz de aumentar em $76 \%$ o "net pay" do poço A. Este resultado parece factível, coerente com os obtidos por Ferraris et al. (2007) que estimaram um aumento em até $116 \%$ nas reservas quando utilizado o perfil de indução multicomponente nos casos de reservatórios interlaminados.

A diferença de "net pay" encontrada para o intervalo 1 foi de $160 \%$ quando utilizado o perfil de indução multi-componente no cálculo de saturação. Esta ferramenta permitiu não somente aumentar o "net gross" do intervalo mas também calcular a saturação de água com base num valor de resistividade mais realista, uma vez que a presença de folhelhos condutivos conduz
Tabela 5 - Comparação entre os resultados de "net pay" e saturação de água para os intervalos analisados utilizando os diferentes métodos.

\begin{tabular}{c|c|c|c}
\hline & Intervalo 1 & Intervalo 2 & Total \\
\hline $\begin{array}{c}\text { "Netpay" } \\
\text { (convencionais) }\end{array}$ & $17,91 \mathrm{~m}$ & $26,67 \mathrm{~m}$ & $44,58 \mathrm{~m}$ \\
\hline $\begin{array}{c}\text { "Netpay" } \\
(3 \mathrm{DEX})\end{array}$ & $46,58 \mathrm{~m}$ & $32,32 \mathrm{~m}$ & $78,9 \mathrm{~m}$ \\
\hline $\begin{array}{c}\text { "Netpay" } \\
\text { (imagem) }\end{array}$ & - & $24 \mathrm{~m}$ & \\
\hline $\begin{array}{c}\text { SW } \\
\text { (convencionais) }\end{array}$ & & $28 \%$ & \\
\hline $\begin{array}{c}\text { SW } \\
(3 \mathrm{DEX})\end{array}$ & \multicolumn{3}{|}{$26,3 \%$} \\
\hline
\end{tabular}

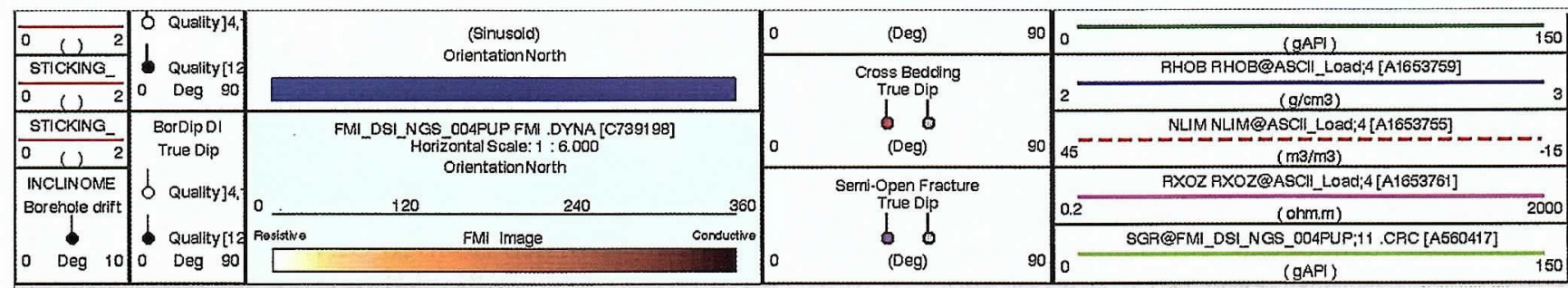

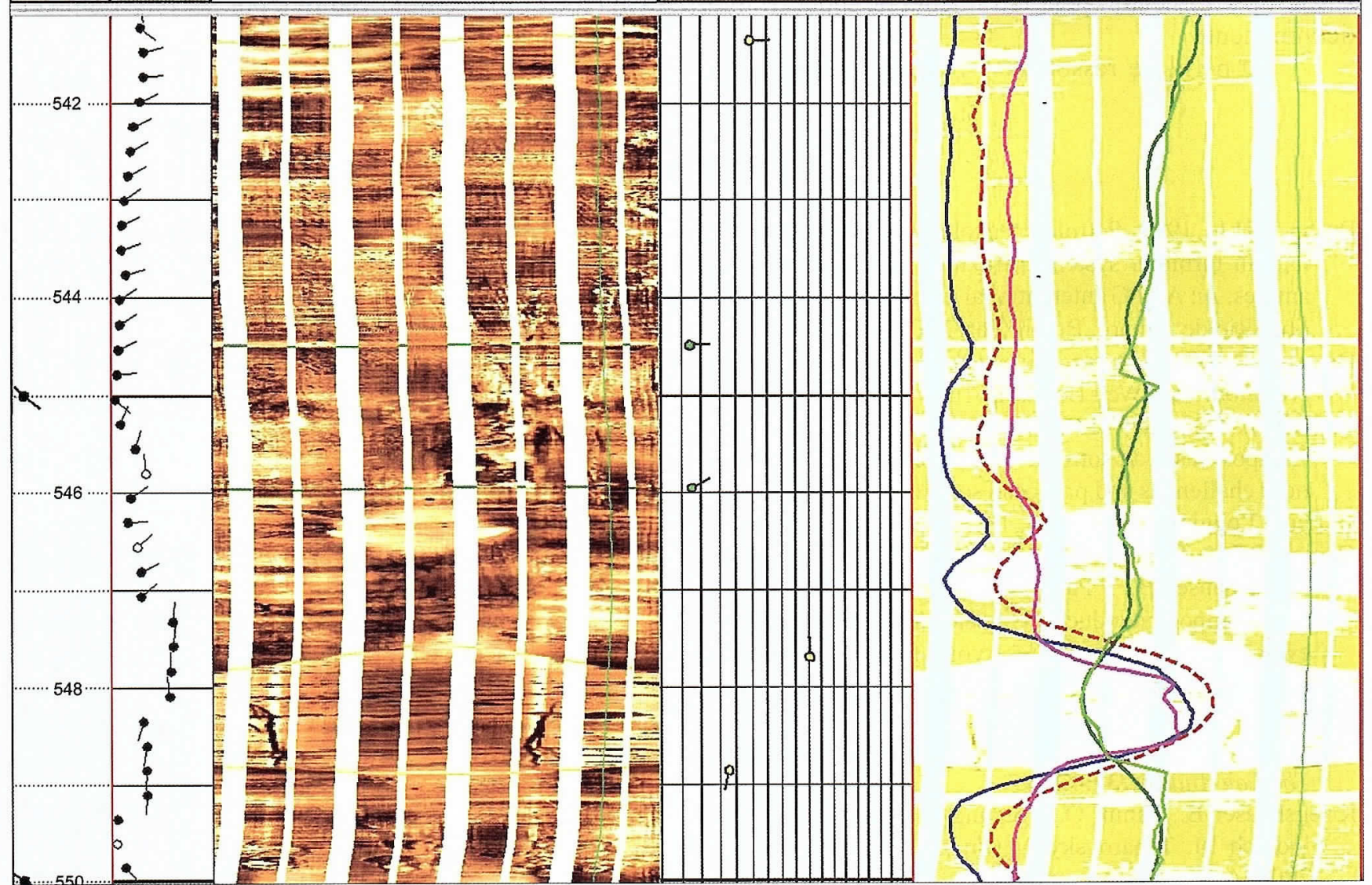

Figura 28 - Perfil de imagem resistiva correspondente ao intervalo X541m a X550m. O intervalo corresponde ao arenito maciço. Pela imagem é possivel perceber que os arenitos encontram-se localmente cimentados. As profundidades tiveram a milhar suprimida. 
a uma diminuição da resistividade lida pela ferramenta de indução convencional.

De forma similar, o intervalo 2 também teve seu "net pay" aumentado, mas neste caso, em aproximadamente $22 \%$.

$\mathrm{O}$ "net pay" encontrado para os intervalos laminados foram calculados com base nas equações derivadas das respostas da ferramenta de indução multicomponente. Principalmente no que tange a zona 1 , este resultado parece estar superestimado uma vez que o perfil de ressonância magnética apresenta fluido livre, mas não em volume que justifique uma aumento tão significativo de "net pay".

A saturação de água calculada com o perfil de indução multi-componente foi menor, o que consequentemente confere a esta ferramenta um resultado mais otimista no que se refere a saturação de óleo.

CONCLUSÕES As fácies interlaminadas, típicas de depósitos de overbank, estão presentes nos turbiditos da bacia de Campos e usualmente exibem anisotropia elétrica. Este efeito se torna importante quando camadas delgadas de areia, saturadas por hidrocarbonetos, estão intercaladas com folhelhos condutores. Não considerar a presença da anisotropia pode levar a uma subestimação dos volumes de óleo presentes no reservatório.

A existência de anisotropia é confirmada por testemunhos e imagens, corroborando o resultado de anisotropia fornecido pela ferramenta de indução multicomponente.

O perfil de ressonância magnética mostra boa correlação com o indução multi-componente, em que uma análise conjunta entre as duas ferramentas possibilita um melhor entendimento do reservatório, principalmente nos intervalos não testemunhados.

As anisotropias de resistividade a partir das ferramentas de indução multicomponente podem ser qualitativamente correlacionadas com os perfis de imagem e as resistividades horizontais da ferramenta multicomponente concordam com as resistividades horizontais obtidas pelos perfis de indução convencionais.

A saturação de hidrocarbonetos baseada nos dados da ferramenta de indução multicomponente (resistividade vertical) são significativamente maiores do que aquelas baseadas nos dados de indução convencional (resistividade horizontal). Os resultados mostram que as reservas seriam substancialmente subestimadas (cerca de $80 \%$ ) utilizando uma análise petrofísica convencional nos casos de reservatórios interlaminados. A obtenção de "net pay" através das imagens resistivas foi a mais pessimista, possivelmente devido a má calibração obtida a partir da curva de resistividade rasa.

Agradecimentos Os autores agradecem as sugestões e criticas dos geólogos Antônio Carlos Nascimento, Fabio Monteiro de Lima, Ana Patrícia Laier, Marcos Domingues, Ricardo Bogado, Cristiano Sombra, Roberto Salvador Francisco d'Ávila, Carlos Emanoel Souza Cruz e ao geofísico Rodrigo Oliveira Carvalho. A autora agradece ao seu filho Gabriel, por ser tão compreensivo nos meus momentos de ausência.

\section{Referências}

Bruhn C.H.L. 1998. Petroleum geology of rift and passive margin turbidite systems: brazilian and worldwide examples. In: AAPG International Conference and Exhibition, Rio de Janeiro, Brazil. Part 2, Course 6.

Dewan J.T. 1983. Essentials of modern open-hole log interpretation. PennWell Books, 361p.

Ferraris P., Coutinho M.R., Meira A.A.G, Adams T. 2007. Campos basin anisotropic turbidities formation evaluation: challenges and proposed solutions. In: SPWLA Annual Logging Symposium, $48^{\text {th }}$, Paper QQ, CDRom.

Gomes R.M., Denicol P.S., Cunha A.M.V., Souza M.S., Kriegshäuser B.F., Payne C.J., Santos A. 2002. Using multicomponent induction $\log$ data to enhance formation evaluation in deepwater reservoirs from Campos basin, offshore Brazil. In: SPWLA Annual Logging Symposium, 43 ${ }^{\text {rd }}$, Paper N, CDRom.

Klein J.D. 1996. Saturation effects on electrical anisotropy. The Log Analyst, 37:47-49.

Kriegshäuser B., Fanini O., Forgang S., Itskovich G., Rabinovich M, Tabarovsky L., Yu L., Epov M., Horst J. 2000. A new multicomponent induction logging tool to resolve anisotropic formations. In: SPWLA Annual Logging SymposiumTransactions, $41^{\text {st }}$, Paper D, CDRom.
Milani E.J., Brandão J.A.S.L, Zalán P.V., Gamboa L.A.P 2000. Petróleo na margem continental brasileira: geologia, exploração, resultados e perspectivas. Revista Brasileira de Geofisica, 18:351-396.

Mollison R. \& Mezzatesta A. 2000. Enhanced evaluation of sand-shale sequences using macroscopic electrical anisotropy. Petrophysics, 44:18-22.

Rangel H.D., Martins F.A.L., Esteves F.R., Feijó F.J. 1994. Bacia de Campos. Boletim de Geociências da Petrobras, 8:203-217.

Souza Cruz C.E. 1995. Estratigrafia e sedimentação de águas profundas do Neogeno da bacia de Campos, Estado do Rio de Janeiro. Tese de Doutoramento, Instituto de Geociências, Universidade Federal do Rio Grande do Sul, 186p.

Yu L., Fanini O.N, Kriegshäuser B.F., Koelman J.M.V., van Popta J. 2001. Enhanced evaluation of low-resistivity reservoirs using multi-component induction log data. Petrophysics, 42:611-623.

Manuscrito BR 15

Submetido em 21 de dezembro de 2007 Aceito em 10 de março de 2008 